\title{
Effects of physical activity and inactivity on muscle fatigue
}

\author{
Gregory C. Bogdanis* \\ Department of Physical Education and Sports Science, University of Athens, Athens, Greece
}

\section{Edited by:}

Christina Karatzaferi, University of

Thessaly, Greece

Reviewed by:

Bruno Bastide, University of Lille Nord de France, University of Lille 1, France Norbert Maassen, University

Hannover/Medical School Hannover, Germany

*Correspondence:

Gregory C. Bogdanis, Department of Physical Education and Sports

Science, University of Athens, 41

Ethnikis Antistasis Street, Dafne, 172

37 Athens, Greece.

e-mail: gbogdanis@phed.uoa.gr
The aim of this review was to examine the mechanisms by which physical activity and inactivity modify muscle fatigue. It is well known that acute or chronic increases in physical activity result in structural, metabolic, hormonal, neural, and molecular adaptations that increase the level of force or power that can be sustained by a muscle. These adaptations depend on the type, intensity, and volume of the exercise stimulus, but recent studies have highlighted the role of high intensity, short-duration exercise as a time-efficient method to achieve both anaerobic and aerobic/endurance type adaptations. The factors that determine the fatigue profile of a muscle during intense exercise include muscle fiber composition, neuromuscular characteristics, high energy metabolite stores, buffering capacity, ionic regulation, capillarization, and mitochondrial density. Muscle fiber-type transformation during exercise training is usually toward the intermediate type IIA at the expense of both type I and IIx myosin heavy-chain isoforms. High-intensity training results in increases of both glycolytic and oxidative enzymes, muscle capillarization, improved phosphocreatine resynthesis and regulation of $\mathrm{K}^{+}, \mathrm{H}^{+}$, and lactate ions. Decreases of the habitual activity level due to injury or sedentary lifestyle result in partial or even compete reversal of the adaptations due to previous training, manifested by reductions in fiber cross-sectional area, decreased oxidative capacity, and capillarization. Complete immobilization due to injury results in markedly decreased force output and fatigue resistance. Muscle unloading reduces electromyographic activity and causes muscle atrophy and significant decreases in capillarization and oxidative enzymes activity. The last part of the review discusses the beneficial effects of intermittent high-intensity exercise training in patients with different health conditions to demonstrate the powerful effect of exercise on health and well being.

Keywords: high-intensity exercise, training, repeated sprints, aerobic training

\section{INTRODUCTION}

Muscle fatigue can be defined as the inability to maintain the required or expected force or power output (Edwards, 1981; Fitts, 1994). Due to the fact that a decrease in muscle performance may ensue even during a submaximal activity, a more appropriate definition of fatigue for any population may be: "any decline in muscle performance associated with muscle activity at the original intensity (Simonson and Weiser, 1976; Bigland-Ritchie et al., 1986). Muscle fatigue is a common symptom during sport and exercise activities, but is also increasingly observed as a secondary outcome in many diseases and health conditions during performance of everyday activities (Rimmer et al., 2012). In many of these health conditions, physical inactivity is a major contributing factor to the increased fatigability of the patient. Deconditioning as a result of restricted physical activity results in large decreases in muscle mass and strength, as well as increased fatigability due to changes in muscle metabolism (Bloomfield, 1997; Rimmer et al., 2012). On the other end of the physical activity spectrum, chronic exercise training increases muscle strength and function, and enhances the ability of the muscles to resist fatigue in healthy individuals and patients of all ages (Bishop et al., 2011; Hurley et al., 2011).

The aim of the present review is to investigate and explain the differences in muscle fatigue between individuals with different physical activity levels histories. The effects of different types of training will be evaluated and compared, while the factors that contribute to muscle fatigue in healthy individuals will be analyzed. Also, the outcomes of an acute or chronic decrease in physical activity due to injury, immobilization, or illness will be examined. Finally, the beneficial effects of exercise in patients with different health conditions will be presented in an attempt to demonstrate the powerful effect of exercise training not only on sport performance, but also on health and well being.

\section{MUSCLE FATIGUE IN INDIVIDUALS WITH DIFFERENT TRAINING BACKGROUNDS}

Training history has an impact on muscle fatigue profile during high-intensity exercise. It is well known that power trained athletes are stronger and faster than both endurance athletes and untrained individuals. Previous studies have shown that power trained athletes have $25-35 \%$ higher maximal voluntary contraction (MVC) force and maximal rate of force development (RFD), as well as peak and mean power compared to endurance athletes (Paasuke et al., 1999; Calbet et al., 2003). When comparing the fatigue profiles of those athletes, a lower peak power but a slower rate of muscle power decline is observed in endurance athletes than in power athletes. This is due to the ability of endurance trained athletes to better maintain their performance during the test as shown 
by their lower fatigue index, calculated as the rate of drop from peak to end power output.

The differences in fatigue between power and endurance trained athletes are more evident when repeated bouts of maximal exercise are performed with short recovery intervals. A common method to examine fatigue in maximal repeated muscle performance is to calculate fatigue during a protocol of short-duration sprints, interspersed with brief recoveries (Bishop et al., 2011). In that case, fatigue index is expressed as the drop of peak or mean power from the first to the last sprint (Hamilton et al., 1991), or preferably as the average decrement of power in all sprints relative to the first sprint (Fitzsimons et al., 1993). According to the later calculation of fatigue, endurance runners had a $37 \%$ smaller power decrement over five $6 \mathrm{~s}$ maximal sprints interspersed with $24 \mathrm{~s}$ rest, compared with team sports players (Bishop and Spencer, 2004). This was accompanied by smaller disturbances in blood homeostasis as reflected by lower post-exercise blood lactate concentration (Bishop and Spencer, 2004). One important factor that may contribute to the slower rate of fatigue and the smaller metabolic disturbances of endurance trained individuals is their higher aerobic fitness. It has been shown that endurance athletes have higher oxygen uptake during a repeated sprint test, indicating a greater contribution of aerobic metabolism to energy supply (Hamilton et al., 1991). The comparison of fatigue profiles between athletes with different training background reveals some possible mechanisms that determine the ability of the muscle to maintain high performance. It is now accepted that the factors causing fatigue may range from central (e.g., inadequate generation of motor command in the motor cortex) to peripheral (e.g., accumulation of metabolites within the muscle fibers (Girard et al., 2011). High-intensity exercise, usually in the form of repeated bouts interspersed with a short interval, can be used as a model to examine muscle fatigue both in health and disease. The recent use of intense interval exercise as a time-efficient and highly effective strategy for training healthy individuals (Burgomaster et al., 2008) and patients with various health conditions (e.g., chronic obstructive pulmonary disease, COPD patients; Vogiatzis, 2011), necessitates understanding of the factors that cause muscle fatigue in this type of exercise.

\section{FACTORS MODIFYING FATIGUE IN PHYSICALLY ACTIVE INDIVIDUALS \\ MUSCLE FIBER COMPOSITION}

It is known for many decades that muscle fiber composition differs between sprint/power trained and endurance trained athletes and untrained individuals (Costill et al., 1976). The traditional distinction between slow and fast muscle fibers based on myosin ATPase, has been replaced by the characterization according to the expression of myosin heavy-chain (MHC) isoforms. The classification of fibers according to $\mathrm{MHC}$ can provide an informative picture about functional characteristics such as strength, power, and fatigue resistance (Bottinelli, 2001; Malisoux et al., 2007). Based on the major MHC isoforms, three pure fiber types can be identified: slow type I and fast type IIA and IIX (Sargeant, 2007). Although these fiber types have similar force per unit cross-sectional area (CSA), they differ considerably in maximum shortening velocity (type I about four to five times slower than IIX) and power generating capacity (Sargeant, 2007). Furthermore, type IIX fibers have an enzymatic profile that favors anaerobic metabolism, namely, high resting phosphocreatine (PCr) content (Casey et al., 1996) and high concentration and activity of key glycolytic enzymes such as glycogen phosphorylase and phosphofructokinase (Pette, 1985). This profile makes the fiber more vulnerable to fatigue due to energy depletion or accumulation of metabolites (Fitts, 2008). On the other hand, type I fibers have a higher content and activity of oxidative enzymes that favor aerobic metabolism and fatigue resistance (Pette, 1985). Thus, muscles with a greater proportion of type I fibers would be more fatigue resistant compared with muscles with a greater proportion of type IIA and type IIX fibers. In this context, endurance trained individuals have a higher percentage of type I slow/fatigue resistant fibers (about 65\% type I fibers in the gastrocnemius muscle; Harber and Trappe, 2008), compared with sprinters (about $40 \%$ type I fibers in the quadriceps; Korhonen et al., 2006), and recreationally active individuals (about 50\% type I fibers in the gastrocnemius muscle; Harber and Trappe, 2008).

The greater fatigability of individuals whose muscles have a high percentage of type II fibers was demonstrated in several studies. For example, Hamada et al. (2003) reported a more than twofold greater decrease in force during repeated maximal voluntary isometric contractions of the quadriceps, in individuals with a high percentage of type II fibers (72\%) compared with individuals with much lower (39\%) type II fibers. Similar findings were reported by Colliander et al. (1988) using repeated bouts of isokinetic exercise. An interesting finding in that investigation was that when blood flow to the leg was occluded using a pneumatic cuff, the decrease in peak force was fivefold greater in the group of subjects with higher percentage of type I muscle fibers. This indicates the reliance of these fibers on blood flow, oxygen availability, and aerobic metabolism (Colliander et al., 1988).

Single fiber studies show that there is a selective recruitment and selective fatigue of the fast fibers containing the IIX MHC isoform, as shown by a large (70\%) decrease of single fiber ATP within 10 s of sprint exercise (Karatzaferi et al., 2001b). At the same time, type I fibers showed no change in ATP. This may suggest that the contribution of the faster and powerful fibers that contain the IIX isoform may be decreased after the first few seconds of high-intensity exercise (Sargeant, 2007). The greater metabolic disturbances in type II compared to type I fibers may be due to the faster rate of $\mathrm{PCr}$ degradation and anaerobic glycolysis and thus lactate and $\mathrm{H}^{+}$accumulation (Greenhaff et al., 1994).

\section{IONIC REGULATION}

During high-intensity exercise large changes in metabolites and ions are observed within the working muscles (Juel et al., 2004; Mohr et al., 2007; Cairns and Lindinger, 2008). Disturbances in the concentration of muscle lactate, hydrogen $\left(\mathrm{H}^{+}\right)$, potassium $\left(\mathrm{K}^{+}\right)$, and calcium $\left(\mathrm{Ca}^{2+}\right)$ ions are linked with fatigue (McKenna et al., 2008) and thus ionic regulation becomes critical for muscle membrane excitation, contraction, and energy metabolism (Allen et al., 2008).

The extensive activation of glycogenolysis and anaerobic glycolysis result in $\mathrm{H}^{+}$accumulation that decreases muscle $\mathrm{pH}$ by about 0.5 unit (McCully et al., 1994; Bogdanis et al., 1995). The ability of 
the muscle to regulate $\mathrm{H}^{+}$and lactate homeostasis during highintensity exercise may play an important role in the fatigue process (Juel, 2008). Several mechanisms contribute to muscle $\mathrm{pH}$ regulation, including release of $\mathrm{H}^{+}$to the blood via different transport systems and buffering of $\mathrm{H}^{+}$within the muscle (Juel, 2008). The most important membrane transport systems involved in $\mathrm{pH}$ regulation are the $\mathrm{Na}^{+} / \mathrm{H}^{+}$exchange, which is considered as the most important, the $\mathrm{Na}^{+} /$bicarbonate co-transport, and the lactate $/ \mathrm{H}^{+}$ co-transport (Juel, 2008).

Although removal of $\mathrm{H}^{+}$and lactate out of the muscle cell are considered important for the restoration of muscle performance following intense contractions, there is evidence to suggest that low $\mathrm{pH}$ and high lactate have far less inhibitory effects on the activation of the contractile apparatus than previously assumed (Allen et al., 2008). This evidence comes mainly from isolated animal muscle and single fiber experiments and suggests that a small part of fatigue is due to increased inorganic phosphate $(\mathrm{Pi})$, that reduces force output, and $\mathrm{K}^{+}$accumulation inside the t-tubules, that affects action potential (Allen et al., 2008). According to this evidence, the greatest part of fatigue, is due to reduced sarcoplasmic reticulum calcium $\left(\mathrm{Ca}^{2+}\right)$ release and decreased $\mathrm{Ca}^{2+}$ sensitivity of the contractile proteins (Allen et al., 2008). An increasing body of data shows that oxidative stress may influence $\mathrm{Ca}^{2+}$ sensitivity and $\mathrm{Ca}^{2+}$ reuptake by the sarcoplasmic reticulum and therefore muscle function and fatigue (Westerblad and Allen, 2011).

\section{EFFECTS OF REACTIVE OXYGEN SPECIES ON SKELETAL MUSCLE MASS AND FUNCTION}

There is growing evidence that reactive oxygen species (ROS) and reactive nitrogen species (RNS) are produced in skeletal muscles under physiological (exercise) as well as under pathological conditions (Lamb and Westerblad, 2011; Pellegrino et al., 2011; Westerblad and Allen, 2011). The most important ROS are: (a) the superoxide anion that is mainly produced in the mitochondria as a by-product of oxidative phosphorylation and by NADPH and xanthine oxidases (b) hydrogen peroxide $\left(\mathrm{H}_{2} \mathrm{O}_{2}\right)$ and (c) hydroxyl radicals (Allen et al., 2008). Although increased ROS are implicated in muscle fatigue, it is becoming increasingly clear that ROS are important components in normal cellular signaling and adaptation (Westerblad and Allen, 2011). ROS can cause muscle fatigue by decreasing maximum $\mathrm{Ca}^{2+}$ activated force, $\mathrm{Ca}^{2+}$ sensitivity, and $\mathrm{Ca}^{2+}$ release, and this was demonstrated by experiments where administration of ROS scavengers/antioxidants delayed fatigue development (Lamb and Westerblad, 2011). From all the administered antioxidant supplements (e.g., ubiquinone-10, vitamins $\mathrm{C}$ and $\mathrm{E}$ ), the antioxidant $\mathrm{N}$-acetylcysteine (NAC) has proven to be the most effective (Hernandez et al., 2012). NAC easily enters cells and contains a thiol group that can interact with ROS and their derivatives (Ferreira and Reid, 2008). Also, as a thiol donor, NAC also supports resynthesis of one of the major endogenous antioxidant systems, glutathione (Hernandez et al., 2012). The endogenous ROS scavenging pathways, such as glutathione peroxidase (GPX) and superoxide dismutase (SOD) activities are substantially up-regulated by exercise training (Allen et al., 2008).

Reactive oxygen species have also been implicated in damage of cell proteins, DNA, and lipids through oxidation and thus have been related with muscle damage and muscle wasting observed in heavy exercise, disuse, and various pathological conditions (Pellegrino et al., 2011). In models of disuse muscle atrophy using hindlimb unloading and limb immobilization, the potential role of oxidative stress in determining muscle wasting has been manifested as an increase in oxidative stress (free iron, xanthine oxidase activity, lipid peroxidation, and oxidized/reduced glutathione ratio), together with an impairment in antioxidant defense systems (decreased catalase and GPX activities) and other protective proteins such as heat shock proteins (Lawler et al., 2003, 2006; Pellegrino et al., 2011). However, the co-existence of oxidative stress and muscle atrophy does not necessarily imply a cause and effect relationship for the hindlimb unloading model. Similarly, data from the few human bed rest studies suggest a decrease in protein synthesis, suggesting anabolic resistance, and not mainly protein breakdown due to oxidative stress (for a review see Pellegrino et al., 2011). However, in respiratory, kidney, and cardiac disease and muscular dystrophy the pivotal role of oxidative stress and increased proteolysis has been suggested (Moylan and Reid, 2007).

\section{CONTRIBUTION OF OXIDATIVE METABOLISM TO ENERGY SUPPLY}

In recent years, data have been accumulated showing the significant contribution or oxidative metabolism to the energy supply during short bouts of all-out exercise, such as sprinting (Bogdanis et al., 1996, 1998; Spencer et al., 2005). An early study by Gaitanos et al. (1993) noted that although the decrease in mean power during $10 \times 6$ s sprints with 30 s rest was $27 \%$, anaerobic energy supply was reduced by almost threefold (70\%), due to diminished contribution of glycolysis to anaerobic ATP turnover. They were the first to suggest that power output during the last sprints was probably sustained by increased contribution of oxidative metabolism. The enhanced contribution of oxidative metabolism to repeated all-out exercise was quantified in a later study using a protocol of two $30 \mathrm{~s}$ sprints separated by $4 \mathrm{~min}$ of passive rest (Bogdanis et al., 1996). Aerobic energy contribution during the first $30 \mathrm{~s}$ sprint was about $29 \%$ and this increased to $43 \%$ during the second $30 \mathrm{~s}$ sprint performed $4 \mathrm{~min}$ later (Figure 1). Interestingly, aerobic contribution was further increased to $65 \%$ of the energy during the last $20 \mathrm{~s}$ of the second sprint, at which point $85 \pm 3 \%$ of $V_{\mathrm{O}_{2}}$ max was attained (Bogdanis et al., 1996 and unpublished calculations from biopsy and oxygen uptake data). An increased aerobic contribution to energy supply during repeated bouts of high-intensity exercise has been reported for endurance trained individuals (Hamilton et al., 1991; Tomlin and Wenger, 2002; Calbet et al., 2003). It is noteworthy that oxygen uptake increases very fast during repeated short-duration sprints $(15 \mathrm{~m} \times 40 \mathrm{~m}$ with $25 \mathrm{~s}$ rest), reaching $80-100 \% V_{\mathrm{O}_{2}}$ max during the last sprints (Dupont et al., 2005).

\section{RATE OF PHOSPHOCREATINE RESYNTHESIS}

Phosphocreatine degradation provides the most immediate and faster source of ATP resynthesis during high-intensity exercise (Sahlin et al., 1998). However, due to the relatively low intramuscular stores, $\mathrm{PCr}$ is exhausted early during a single bout of high-intensity exercise. However, $\mathrm{PCr}$ is rapidly resynthesized during the recovery following exercise and thus the rate of $\mathrm{PCr}$ 

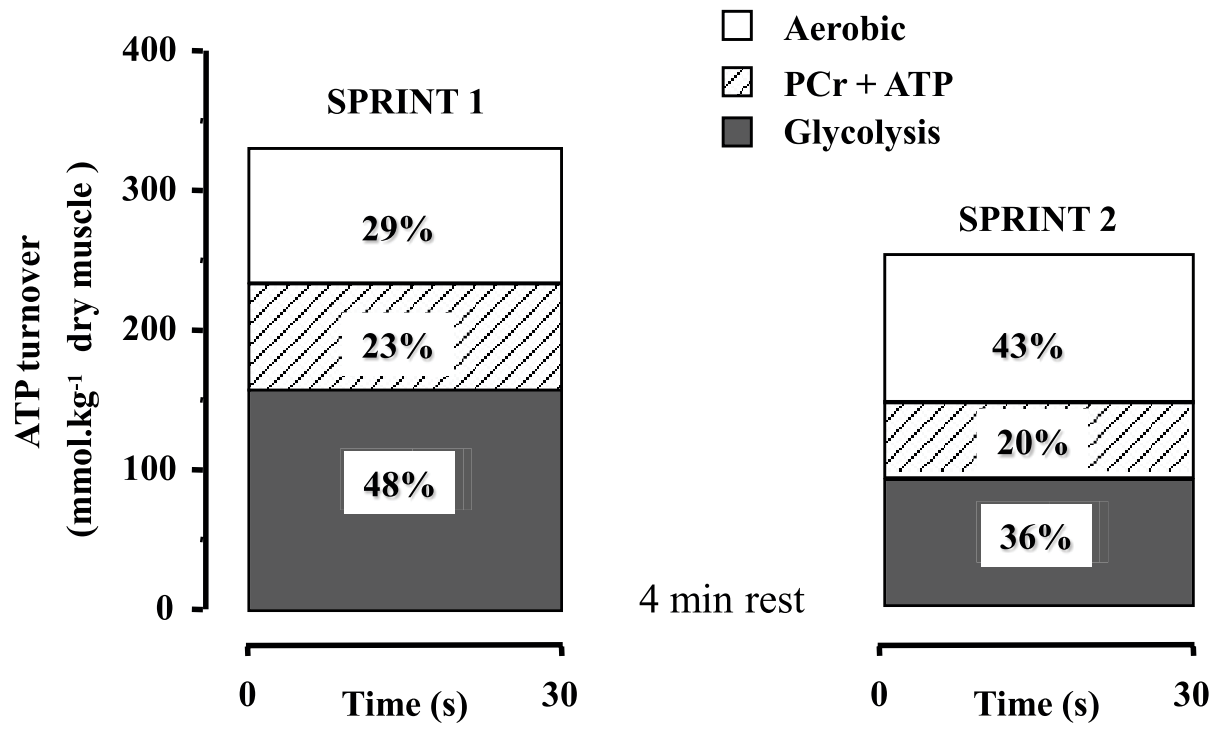

FIGURE 1 | Calculated ATP turnover (percent contribution) from ATP + PCr degradation, anaerobic glycolysis, and aerobic metabolism during two 30 s sprints separated by 4 min of recovery Redrawn using data from Bogdanis et al. (1996).

resynthesis determines its availability for the next exercise bout. Consequently, individuals with fast $\mathrm{PCr}$ resynthesis exhibit greater fatigue resistance during repeated bouts of high-intensity exercise (Bogdanis et al., 1996; Casey et al., 1996; Johansen and Quistorff, 2003). PCr resynthesis depends highly on oxygen availability (Haseler et al., 1999, 2007). The rate of PCr resynthesis measured by phosphorus nuclear magnetic resonance spectroscopy has been widely used as an index of muscle oxidative capacity (Haseler et al., 2004). Johansen and Quistorff (2003) have examined the differences in PCr resynthesis and performance recovery between endurance trained, sprint trained, and untrained individuals using phosphorus nuclear magnetic resonance spectroscopy. Participants performed four maximal isometric contractions of $30 \mathrm{~s}$ duration, interspersed by $60 \mathrm{~s}$ recovery intervals. Endurance trained athletes showed almost twice as fast PCr resynthesis rate compared to sprint trained and untrained participants (half time, $t_{1 / 2}: 12.5 \pm 1.5$ vs. $22.5 \pm 2.5$ vs. $26.4 \pm 2.8 \mathrm{~s}$, respectively). This resulted in almost complete restoration of PCr stores prior to each contraction for the endurance athletes, whereas the untrained and the sprinters started the subsequent contractions with a PCr level of about $80 \%$ of baseline. There is evidence to suggest that the faster rate of $\mathrm{PCr}$ resynthesis in endurance athletes is probably not related to $V_{\mathrm{O}_{2} \text { max }}$. The relationship between $V_{\mathrm{O}_{2} \text { max }}$ and PCr resynthesis has been questioned, since it has been shown that individuals with high and low $V_{\mathrm{O}_{2} \max }(64.4 \pm 1.4$ vs. $46.6 \pm 1.1 \mathrm{ml} \mathrm{kg}^{-1} \mathrm{~min}^{-1}, P<0.01$ ) have similar $\mathrm{PCr}$ resynthesis rates (Cooke et al., 1997). Furthermore, individuals with equal $V_{\mathrm{O}_{2} \text { max }}$ levels may have remarkably different endurance capacity because of differences in "peripheral" or muscle characteristics such as muscle capillary density and onset of blood lactate accumulation (Coyle et al., 1988). Thus, it may be suggested that the faster rate of PCr resynthesis in endurance trained individuals is most probably related with adaptations that favor blood flow and oxygen delivery and utilization in the muscle, such as increased mitochondrial content, capillary density and oxidative enzyme content and activity (Andersen and Henriksson, 1977; Tesch and Wright, 1983; Tesch et al., 1985; Karatzaferi et al., 2001a). The role of peripheral adaptations on PCr resynthesis has also been indirectly demonstrated by the high positive correlation $(r=0.89$, $P<0.01$ ) between the percent PCr resynthesis 4 min after a $30-\mathrm{s}$ sprint and endurance fitness as determined from the percentage of $V_{\mathrm{O}_{2}}$ max corresponding to a blood lactate concentration of $4 \mathrm{mmoll}^{-1}$ (Bogdanis et al., 1996).

\section{NEURAL FACTORS}

The level and the type of physical activity have an impact on the functional organization of the neuromuscular system. Power trained athletes have been shown to be more affected by fatiguing exercise than endurance athletes (Paasuke et al., 1999). Electromyographic (EMG) activity of the agonist and antagonist muscles and the level of voluntary activation of motor units have been traditionally used to examine the contribution of neural factors on muscle fatigue. A failure to fully activate the muscles that contribute to force or power output would imply the importance of neural factors in affecting the rate of muscle fatigue.

Changes in the normalized EMG amplitude (root mean square, RMS) of the vastus lateralis muscle during $10 \times 6 \mathrm{~s}$ sprints interspersed by 30 s rest explained $97 \%$ of the total work done, suggesting that fatigue is accompanied by reductions in neural drive and muscle activation (Mendez-Villanueva et al., 2008). However, the parallel decrease of EMG activity and power output may imply that the decreased neural drive may be the consequence and not the cause of the decreased performance. Amann and Dempsey (2008) demonstrated that feedback from group III/IV muscle afferents exerts an inhibitory influence on central motor drive, so that to avoid excessive development of peripheral fatigue beyond a sensory tolerance limit associated with potential muscle tissue damage. 
A common finding in many studies assessing neuromuscular activity is that fatigue in high-intensity exercise is characterized by a shift in the EMG power spectrum of the muscles involved, possibly indicating selective fatigue of fast-twitch fibers (Kupa et al., 1995; Billaut et al., 2006). This selective fatigue of the fast-twitch fibers may be related with increased fatigue in individuals with a high percentage of fast fibers.

Another neuromuscular characteristic that may be affected by physical activity level is voluntary activation. Voluntary activation of a muscle during an MVC can range from 80 to $100 \%$ (Behm et al., 2002). When a muscle is sub maximally activated during an MVC (e.g., 70\% of its full capacity), fatigue is likely to develop at a slower rate than if it was fully activated. Sub-optimal muscle activation during maximal effort is commonly observed in children performing high-intensity exercise and is one of the reasons that young individuals fatigue less compared with adults (Ratel et al., 2003). However, sub-optimal muscle activation is not uncommon in adults. Nordlund et al. (2004) reported a wide range of voluntary activation (67.9-99.9\%) for the plantar flexors of healthy habitually active males. A novel finding of that study was that a large percentage $(58 \%)$ of the variance in fatigue during repeated short maximal isometric contractions was explained by the magnitude of MVC torque and the initial percent voluntary activation. This finding provides support to the suggestion that individuals who cannot fully activate their muscles fatigue less but are able to generate much less force and muscle power. This may be related with a failure to recruit all fast-twitch fibers results, which, in turn, results in less metabolic disturbances and less fatigue during highintensity exercise. It must be noted that the level of voluntary activation is reduced with fatigue, as shown by a study by Racinais et al. (2007), who reported a decrease in voluntary activation from 95 to $91.5 \%(P<0.02)$, along with a $10 \%$ decrease in peak power and an about $17 \%$ decrease in MVC following ten $6 \mathrm{~s}$ sprints.

Fatigue during high-intensity dynamic exercise may become greater due to the loss of synchronization between agonist and antagonist muscles and the increased level of co-contraction of the antagonists muscles. This would decrease the effective force or power generated by a joint, especially during faster movements where neuromuscular coordination is more important. Garrandes et al. (2007) reported that the co-activation level of the antagonist muscles during knee extension was increased by $31 \%$ after fatigue only in power trained and not in endurance athletes. Earlier findings by Osternig et al. (1986) showed a four times higher hamstrings co-activation during isokinetic knee extensions in sprinters compared with distance runners (57 vs. $14 \%$ ), probably indicating a sport-specific adaptation. The higher antagonist coactivation in sprint/power trained individuals may partly explain their greater fatigue during dynamic exercise, since part of the agonist force/power is lost to overcome antagonist muscle activity. However, Hautier et al. (2000) reported that the lower activation of the antagonist knee flexor muscled due to fatigue appeared to be an efficient adaptation of the inter-muscular coordination to modulate the net force generated by the fatigued agonists and maintain the force applied on the pedals.

\section{INFLUENCE OF INITIAL FORCE OR POWER ON MUSCLE FATIGUE}

Fatigue is traditionally calculated as the drop of force or power from an initial value to the lowest or end value. A common observation when examining fatigue is that individuals who can generate high force or power per kg body or muscle mass, usually fatigue quicker (Girard et al., 2011). Previous studies have reported that initial sprint performance is strongly correlated with fatigue during a repeated sprint test (Hamilton et al., 1991; Bishop et al., 2003) and inversely related to maximal oxygen uptake (Bogdanis et al., 1996). In fact, when comparing endurance and sprint trained athletes, relative power output (per kg body mass) is only different at the initial part of the exercise bout and thereafter performance is similar or even greater in endurance athletes (Calbet et al., 2003). A high force or power output (per kg body mass) during the first part of a high intensity bout may imply high reliance on fast-twitch fibers and anaerobic metabolism and thus greater metabolic disturbances. Thus, the greater fatigue of more powerful athletes may be more related to differences in fiber-type contribution and energy metabolism than a greater initial force or power.

Tomlin and Wenger (2002) and later Bishop and Edge (2006) investigated the influence of the initial power output on fatigue during high-intensity exercise, by comparing two groups of female team sports athletes who had similar peak and mean power output in a 6-s cycle ergometer sprint, but different maximal oxygen uptake values (low $V_{\mathrm{O}_{2} \text { max }}: 34-36$ vs. moderate $V_{\mathrm{O}_{2} \text { max }}$ : 47$\left.50 \mathrm{ml} \mathrm{kg}^{-1} \mathrm{~min}^{-1}\right)$. These athletes were required to perform five $6 \mathrm{~s}$ sprints with $24 \mathrm{~s}$ recovery (Bishop and Edge, 2006) or ten $6 \mathrm{~s}$ sprints with 30 s recovery (Tomlin and Wenger, 2002). Even though the two groups were matched for initial sprint performance, the moderate $V_{\mathrm{O}_{2}}$ max group had a smaller power decrement across the 10 (low vs. moderate: $18.0 \pm 7.6$ vs. $8.8 \pm 3.7 \%, P=0.02$ ) or the 5 sprints (low vs. moderate: $11.1 \pm 2.5$ vs. $7.6 \pm 3.4, P=0.045$ ). These results point to an important role of aerobic fitness on the ability to resist fatigue.

Mendez-Villanueva et al. (2008) investigated this issue by calculating the anaerobic power reserve of each individual. This was quantified as the difference between the maximal anaerobic power measured during a 6-s sprint and the maximal aerobic power determined during a graded test to exhaustion. Individuals with a lower anaerobic power reserve, who had less reliance on anaerobic metabolism, showed a greater resistance to fatigue. This suggests that the relative contribution of the aerobic and anaerobic pathways to energy supply and not the initial power per se, provide a better explanation for fatigue during repeated bouts of high-intensity exercise (Mendez-Villanueva et al., 2008).

\section{CHANGES IN FATIGABILITY FOLLOWING EXERCISE TRAINING}

A systematic change in functional demands posed on skeletal muscle will result in adaptations that increase performance toward the characteristics of the exercise stimulus. Depending on the stimulus, skeletal muscle can increase its size (D'Antona et al., 2006), alter muscle fiber-type composition (Malisoux et al., 2007), increase enzyme activities (Green and Pette, 1997), and modify muscle activation (Bishop et al., 2011). The adaptations that may reduce muscle fatigue during high-intensity exercise depend on the characteristics of the training program, i.e., type, intensity, frequency, and duration. Muscle fatigue will be reduced by appropriate shifts in fiber type, enhanced enzyme activity, regulation of ionic balance, and changes in muscle activation. 


\section{SKELETAL MUSCLE FIBER-TYPE SHIFTING DUE TO TRAINING}

Differences in muscle fiber-type distribution between athletes of various sports reflect a combination of two factors: (a) natural selection, i.e., individuals with a high percentage of fast-twitch fibers follow and excel in a sport that requires speed and power, and (b) training-induced fiber-type transformation, i.e., small changes in muscle fiber-type distribution due to long term sport-specific training. Training studies show that it is possible to attain some degree of MHC transformation even with shorter term training (Malisoux et al., 2007). Transitions between MHC isoforms are done in a sequential, reversible order from type I $\leftrightarrow$ type IIA $\leftrightarrow$ type IIX and vice versa (Pette and Staron, 1997; Stevens et al., 1999). This shifting is determined by the neural impulse patterns, the mechanical loading characteristics, and by alterations in the metabolic homeostasis (Pette, 1998). In addition to the pure fiber types there are hybrid fibers co-expressing I and IIA or IIA and IIX MHC isoforms. There is evidence to suggest that the relative proportion of hybrid fibers may increase with training, so that the functional characteristics of the muscle are improved. For example, endurance training may increase the percentage of type I fibers co-expressing fast and slow isoforms, making them faster without losing fatigue resistance (Fitts and Widrick, 1996; Fitts, 2003).

The typical response following high-intensity sprint or heavy resistance training is a shifting of the faster (type IIX) fibers toward the intermediate type IIA fibers, with the percentage of type I fibers either decreasing or remaining unchanged (Esbjörnsson et al., 1993; Ross and Leveritt, 2001; Andersen and Aagaard, 2010). Most data from sprint training studies show that the MHC IIX isoforms are down-regulated and there is usually a bidirectional change toward IIA at the expense of both I and IIX MHC isoforms (Esbjörnsson et al., 1993; Andersen et al., 1994; Ross and Leveritt, 2001). However, an increase in slow twitch at the expense of the fast-twitch fibers has been reported following 7 weeks of sprint training (Linossier et al., 1993). It should be noted that there are very few pure type IIX fibers in skeletal muscles of healthy individuals, while most of the MHC IIX protein is found together with MHC IIA protein in hybrid fibers (Andersen et al., 1994; Malisoux et al., 2007). As will be discussed later in this review, pure type IIX fibers appear most often in disused muscles.

The functional adaptations of muscle fibers following sprint and strength training depend mainly on increases in fiber CSA, with the force per unit of CSA remaining unchanged in most (Widrick et al., 2002; Malisoux et al., 2007), but not in all studies (D'Antona et al., 2006). Maximal shortening velocity of single fibers also seems to be unchanged after resistance (Widrick et al., 2002) or sprint training (Harridge et al., 1998) in healthy young individuals, but there is some evidence that plyometric training may increase maximal shortening velocity in single fibers (Malisoux et al., 2007).

Training the muscle with lower intensity and longer duration stimuli, as used in endurance training, brings about different adaptations. Studies preformed over the last four decades by Pette and colleagues demonstrated the remarkable degree of transformation of fast, fatigable muscles toward slower, fatigue resistant in terms of both fiber type and metabolism using chronic low-frequency stimulation (Pette and Vrbova, 1999). Although this situation is not realistic, it demonstrated that activity may have a large impact on the phenotype and fatigue profile of skeletal muscle. Similar, but to a much lesser degree, effects on muscle fiber composition are seen during endurance training. Trappe et al. (2006) trained recreational runners so that they could compete in a Marathon after 16 weeks ( 13 weeks training and 3 weeks tapering). They reported a decrease in slow (MHC I) and fast (MHC IIA) fiber CSA by about 20\%, but an increase in the percentage of MHC I fibers (from $48 \pm 6$ to $56 \pm 6 \%, P<0.05$ ), while the percentage of MHC IIA fibers remained unchanged $(30 \pm 5 \%$,). A significant finding of that study was that single fiber muscle power expressed per unit fiber volume as measured in vitro, was increased by $>70 \%$ in both MHC I and IIA fibers. These increases of power demonstrate that high-volume endurance training $(30-60 \mathrm{~km}$ running per week) can modify the functional profile of the fibers that are most involved.

It seems therefore that fiber-type profile can be affected to some extent by both high intensity (sprint, strength, power) and endurance training in healthy individuals. The bidirectional shifts of the fast (type IIX) and slow (type I) fiber types toward the intermediate IIA isoform do not guarantee that fatigability will be improved. Factors such as changes in the metabolic properties (e.g., oxidative capacity) of all fiber types with training (Fitts and Widrick, 1996) as well as neural activation patterns of the contracting muscle may play an important role in fatigue resistance and should also be considered together with fiber type shifts. There is growing evidence suggesting that the functional properties of muscle fibers can change in several physiological and pathological conditions with no significant shift in myosin isoforms. This does not negate the important role of muscle fiber composition on fatigue, but rather shows that a "fine tuning" of one or more characteristics of a given fiber may be done according to functional demands (Malisoux et al., 2007).

\section{INCREASES IN ENZYME ACTIVITIES}

The metabolic profile of each muscle fiber is sensitive to training, even when no fiber-type transformation occurs (Pette, 1998). The majority of investigations have reported increases in the activity of key enzymes of glycolysis, such as glycogen phosphorylase, phosphofructokinase (PFK), and lactate dehydrogenase (LDH) following sprint training (Linossier et al., 1993, 1997; Dawson et al., 1998). Linossier et al. (1993) trained young students with repeated short sprints ( $5 \mathrm{~s}$ sprint $55 \mathrm{~s}$ rest) for 7 weeks with four sessions per week. The number of sprints per session was increased every week from 16 to 26 sprints per session. This program resulted in increased energy production from anaerobic glycolysis, as indicated by the increased muscle lactate accumulation after compared to before training ( $\Delta$ lactate $37.2 \pm 17.9$ vs. $52.8 \pm 13.5 \mathrm{mmol} \mathrm{kg}^{-1}$ dry weight $P<0.01)$ and the $20 \%$ higher PFK and LDH activity. A similar training study by Dawson et al. (1998) involving short running sprints of comparable duration to the previous study $(30-60 \mathrm{~m})$ found a $40 \%$ increase in glycogen phosphorylase, but no increase in PFK. A common finding of these two studies involving short sprints was that the activities of key oxidative enzymes involved in carbohydrate metabolism, e.g., citrate synthase (CS) or lipid oxidation, e.g., 3-hydroxyacyl-CoA dehydrogenase (HAD), were either unchanged (Linossier et al., 1993, 
1997) or decreased (Dawson et al., 1998) with this type of repeated short sprint exercise.

However, data from sprint training studies using longer sprint durations such as $30 \mathrm{~s}$ sprints, showed increases in oxidative enzymes. For example, MacDougall et al. (1998) trained their subjects three times per week for 7 weeks using repeated $30 \mathrm{~s}$ sprints with 3-4 min rest in each session. The number of sprints increased progressively from 4 to 10 per session. This training program resulted in a significant increase in the total work done during the last three of the $4 \times 30 \mathrm{~s}$ sprint test protocol. This was accompanied by a $49 \%$ increase in PFK activity $(P<0.05)$ and 36 and $65 \%$ increases in CS and succinate dehydrogenase $(\mathrm{SDH}$, $P<0.05)$. Also an increase in $V_{\mathrm{O}_{2}}$ max from $51.0 \pm 1.8$ to $54.5 \pm 1.5$ $(P<0.05)$ was reported, suggesting that repeated long sprints $(30 \mathrm{~s})$ constitute a powerful aerobic stimulus. In a similar training study with repeated $30 \mathrm{~s}$ cycle ergometer sprints, there was a 7.1\% increase in mean power over a 30 -s sprint and an $8 \%$ increase in $V_{\mathrm{O}_{2} \text { max }}$ (Barnett et al., 2004). Interestingly, these authors reported a $42 \%$ increase in CS activity but no increase in PFK or anaerobic energy provision from $\mathrm{PCr}$ or glycolysis. They suggested that the improvement in $30 \mathrm{~s}$ sprint performance was probably mediated by increased energy provision from oxidative metabolism.

\section{HIGH-INTENSITY TRAINING: A POWERFUL AND TIME-EFFICIENT EXERCISE STIMULUS}

The adaptations caused by high-intensity exercise training have first been examined by Dudley et al. (1982), who reported that fast-twitch fibers respond to training by increasing cytochrome $c$, only when intensity was high. A decade later, McKenna and his research group started investigating the effects of sprint training on ionic balance (McKenna et al., 1993). As discussed in a previous section of this review, Bogdanis et al. (1996) were the first to demonstrate a large increase in oxidative metabolism coupled by a decrease in anaerobic glycolysis when a 30-s sprint was repeated after $4 \mathrm{~min}$ or recovery. The increase in aerobic metabolism and the decrease in glycolysis were possibly mediated by changes in key enzyme activities, such as glycogen phosphorylase, PFK, and pyruvate dehydrogenase (PDH). Parolin et al. (1999) reported an inhibition of glycogen phosphorylase transformation to the more active form due to increased $\mathrm{H}^{+}$concentration at the last of three $30 \mathrm{~s}$ sprints performed with a 4 -min rest. At the same time $\mathrm{PDH}$ activity was enhanced possibly due to the increased $\mathrm{H}^{+}$concentration, resulting in a better matching between pyruvate production and oxidation and minimal muscle lactate accumulation. Repeated high-intensity bouts lasting from $30 \mathrm{~s}$ (Stepto et al., 1999) to $4 \mathrm{~min}$ (Helgerud et al., 2001) are used since then to improve endurance performance in several sports. These early studies indicated that repeated bouts of intense exercise rely heavily on aerobic energy supply and formed the bases for the increasingly popular highintensity exercise interval training (high-intensity training, HIT) concept.

A series of more recent studies by Burgomaster et al. (2005, 2006, 2008) have shown that training with repeated 30 s sprints results in large increases in oxidative enzymes such as CS (by $38 \%$ ), cytochrome $c$ oxidase (COX), and HAD. These adaptations were achieved with only six training sessions performed over 2 weeks with 1-2 days rest (four to seven sprints $30 \mathrm{~s}$ sprints per session with 4 min rest) and were accompanied by a remarkable $100 \%$ increase in endurance capacity as defined by time to exhaustion at $80 \% V_{\mathrm{O}_{2} \max }$ (from $26 \pm 5$ to $51 \pm 11 \mathrm{~min}, P<0.05$ ). The authors have proposed the repeated $30 \mathrm{~s}$ sprint method as a time-efficient training strategy to simultaneously improve aerobic and anaerobic fitness and reduce fatigue. The extremely low time commitment $(2.5 \mathrm{~min}$ per session for $5 \times 30 \mathrm{~s}$ sprints, or less than 20 min including the 4 -min rest intervals) makes this method attractive and further research is warranted to examine its possible applications in health and disease. The basis for the usefulness of this exercise scheme in both sports and clinical settings is that the exercise stimulus induces rapid phenotypic changes that resemble traditional endurance training and promotes mitochondrial biogenesis (Gibala, 2009) which appear to stimulate other healthy metabolic adaptations in skeletal muscle, such as improved insulin action, improved lipoprotein lipase activity and greater clearance of plasma triglycerides (Coyle, 2005).

Following the pioneering study by Burgomaster et al. (2005), Gibala et al. (2006) compared the typical HIT protocol (i.e., 4-6 $\times 30 \mathrm{~s}$ sprints with $4 \mathrm{~min}$ rest) with traditional endurance exercise (90-120 min of continuous cycling at $\left.65 \% \quad V_{\mathrm{O}_{2} \max }\right)$ performed three times per week for 2 weeks. The two protocols resulted in similar increases in muscle oxidative capacity as reflected by the activity of COX and a similar improvement in an endurance time trial (by 10.1 and $7.5 \%$ ). The key role the increase of the active form of pyruvate dehydrogenase (PDH) after this type of training was highlighted in the study of Burgomaster et al. (2006) who also reported a concomitant reduction in glycogenolysis (from $139 \pm 11$ to $100 \pm 16 \mathrm{mmol} \mathrm{kg}^{-1}$ dry weight, $P=0.03$ ) and lower lactate accumulation possibly due to greater mitochondrial pyruvate oxidation. The lower level of acidification due to decreased glycogenolysis may have contributed to reduced fatigability following this type of training.

It should also be stressed that this type of repeated sprint exercise also increases $V_{\mathrm{O}_{2} \text { max }}$ and improves cardiovascular function. Astorino et al. (2012) reported a $6 \%$ increase in $V_{\mathrm{O}_{2} \text { max }}$, oxygen pulse and power output, in only six sessions of HIT involving repeated 30 s sprints over 2-3 weeks. However, in athletic populations, the importance of lower intensity-high-volume training should not be overlooked. Laursen (2010) in a critical review of low and high volume and intensity training suggested that training for sports performance should have an appropriate blend of both HIT and high-volume training, otherwise performance ability can stagnate. A polarized approach for optimal intensity distribution for the training of elite athletes of intense events (rowing, swimming, track running, and cycling) was suggested by Laursen (2010), whereby $75 \%$ of total training volume should be performed at low intensities, and 10-15\% should be performed at very high intensities.

Another form of high-intensity interval training is called "aerobic interval training" and usually consists of four exercise bouts of 4 min each, at an intensity corresponding to $90-95 \%$ of peak heart rate or $85-90 \% V_{\mathrm{O}_{2} \text { max }}$, with 2-3 min or rest in between (Wisloff et al., 2007). This type of training is commonly used in soccer in the form of running or small sided games and has been proved to be very effective in delaying soccer specific or game fatigue. A comparison between the effectiveness of this training protocol 
with a repeated sprint protocol has been performed by Ferrari Bravo et al. (2008). They compared the effects of training with a $4 \times 4$ min running at $90-95 \%$ of maximal heart rate, with 3 min active recovery vs. a repeated sprint training protocol that included three sets of six $40 \mathrm{~m}$ all-out "shuttle" sprints with $20 \mathrm{~s}$ passive recovery between sprints and $4 \mathrm{~min}$ between sets. The repeated sprint group, compared with the aerobic interval training group, showed a greater improvement not only in repeated sprint performance, but also in the soccer specific "Yo-Yo" intermittent recovery test $(28.1$ vs. $12.5 \%, P<0.01)$. A similar improvement in $V_{\mathrm{O}_{2} \max }$ $(6 \%)$ was found for the two groups. As noted above, the adaptations and improvements following HIT of either form (aerobic interval and repeated sprints) are far superior and time-efficient compared with longer duration continuous training. As will be discussed later, the benefits of high-intensity interval exercise of both forms (30s-4 min high-intensity bouts) extend to health promotion and are currently proposed for improving health and reducing fatigue in many diseases (COPD and cardiac patients).

\section{MOLECULAR BASES FOR ADAPTATIONS TO HIT}

Understanding the multiple benefits of HIT requires investigation of the molecular signals that cause adaptations at the level of the skeletal muscle fiber. According to Coffey and Hawley (2007), there are at least four primary signals, as well as a number of secondary messengers, that are related with mitochondrial adaptations and glucose transport capacity across the sarcolemma:

(1) Mechanical tension or stretch,

(2) Oxidative stress manifested by an increase in ROS.

(3) Increase in intracellular calcium with each contraction.

(4) Altered energy status, as reflected by a lower ATP concentration.

Some putative signaling cascades promoting skeletal muscle mitochondrial biogenesis in response to high-intensity interval training may be as follows (Gibala et al., 2012): during intense muscle contractions, the rise in intracellular calcium activates the mitochondrial biogenesis messenger calmodulin kinase. At the same time, the "energy crisis" that results in decreased ATP and increased adenosine mono phosphate (AMP) activates the AMPactivated protein kinase (Gibala, 2009; Laursen, 2010). Activation of p38 mitogen-activated protein kinase (MAPK), possibly via increase generation of ROS may also be involved (Gibala et al., 2012). These signals can increase a key transcriptional coactivator, namely the peroxisome proliferator-activated receptor- $\gamma$ coactivator-1 $\alpha$ (PGC-1 $\alpha$ ), which is a key regulator of oxidative enzyme expression in skeletal muscle. PGC-1 $\alpha$ has been described as a "master switch" that coordinates mitochondrial biogenesis by interacting with various nuclear genes encoding for mitochondrial proteins (Gibala, 2009; Gibala et al., 2012). Previous work has shown that an increased expression of PGC- $1 \alpha$ in the muscle results in the conversion of the muscle from glycolytic to oxidative with a dramatic up-regulation of typical oxidative genes/proteins like COX. This results in a shift of the functional capacity of the muscle toward a more fatigue resistance profile found in the endurance trained state. Calvo et al. (2008) demonstrated that up-regulation of PGC-1 $\alpha$ in transgenic mice, results in far superior exercise performance and 20\% higher peak oxygen uptake compared with wild-type control mice. It is noteworthy that in the study of Burgomaster et al. (2008) which compared typical endurance training with HIT, PGC- $1 \alpha$ protein content of the quadriceps muscle was equally increased in both protocols, demonstrating the large potential of the repeated sprint protocol to produce rapid mitochondrial adaptations. As suggested by Coyle (2005), one of the advantages of the repeated sprint protocol over the traditional endurance exercise, lays on the high level of type II muscle fiber recruitment that is not achieved in the traditional low intensity endurance exercise. Thus, HIT results in mitochondrial adaptations also in type II fibers that are absent when lower intensity/high-volume endurance training is performed. These adaptations of type II fibers would also increase their fatigue resistance and this is beneficial for high-intensity performance.

\section{CHANGES IN MUSCLE FIBER CAPILLARY SUPPLY AND REGULATION OF IONIC BALANCE}

As noted in the previous sections, the improvement in fatigue resistance is partly due to an increase in the enzymes that favor oxidative metabolism. However, a proliferation of capillary supply to muscle fibers would cause an additional improvement in fatigue resistance by enhanced lactate and $\mathrm{H}^{+}$elimination and oxygen supply (Tesch and Wright, 1983). Additional to the role of the different lactate and $\mathrm{H}^{+}$transport mechanisms out of the exercising muscle, improved perfusion contributes to the increased release from muscle to the blood (Juel, 2008). HIT training with intense leg extension exercise three to five times per week for 7 weeks ( 1 min exercise, 3 min rest for $1 \mathrm{~h}$ at $\sim 150 \%$ of leg $V_{\mathrm{O}_{2} \text { max }}$ ) resulted in an increase of capillary-to-fiber ratio from $1.74 \pm 0.10$ to $2.37 \pm 0.12$ capillaries per fiber, and a $17 \%$ increase in capillary density (Jensen et al., 2004). These adaptations would increase oxygen extraction and facilitate aerobic metabolism during exercise as well as the rate of $\mathrm{PCr}$ resynthesis during the recovery intervals (McCully et al., 1991).

In a recent review, Iaia and Bangsbo (2010) presented the benefits of "speed endurance" training, which is a form of repeated HIT. The characteristics of this type of training are as follows: The form or exercise is running and the intensity is between 70 and $100 \%$ of the maximum running speed, which corresponds to a cardiorespiratory load very close or well above $V_{\mathrm{O}_{2}}$ max . The number of repetitions is between 3 and 12 repetitions and the duration of each bout is $10-40 \mathrm{~s}$ (usually $30 \mathrm{~s}$ ) with a recovery interval greater than five times the exercise duration (usually 2-4 min). In well trained athletes, this type of training causes adaptations that do not appear to depend on changes in $V_{\mathrm{O}_{2} \text { max }}$, muscle substrate levels, glycolytic and oxidative enzymes activity. Instead they appear to be related to improved running economy, and a higher expression of muscle $\mathrm{Na}^{+}, \mathrm{K}^{+}$pump $\alpha$-subunits, which may delay fatigue during intense exercise by increasing $\mathrm{Na}^{+}-\mathrm{K}^{+}$pump activity and a reduced contraction-induced net loss of $\mathrm{K}^{+}$, thus preserving muscle excitability (Iaia and Bangsbo, 2010). These conclusions were based on previous studies that compared the effects of two different intense training regimens on changes in muscle ATPase subunits and fatigue.

Mohr et al. (2007) divided participants into a sprint training group $(15 \times 6 \mathrm{~s}$ sprints with $1 \mathrm{~min}$ rest) and a speed endurance 
group $\left(8 \times 30\right.$ s runs at $130 \% V_{\mathrm{O}_{2}}$ max , with 1.5 min rest $)$. Training was performed three to five times per week and lasted for 8 weeks. The fatigue index during a $5 \mathrm{~m} \times 30 \mathrm{~m}$ sprint running test with $25 \mathrm{~s}$ active recovery, was reduced by $54 \%$ only in the speed endurance group, and remained unchanged in the sprint group. The reduction in fatigue was accompanied by a $68 \%$ increase in $\mathrm{Na}^{+}-\mathrm{K}^{+}$ATPase isoform $\alpha 2$ and a $31 \%$ increase in the amount of the $\mathrm{Na}^{+} / \mathrm{H}^{+}$exchanger isoform, only in the speed endurance group. These adaptations are possibly related with the metabolic responses (and thus metabolic load) during each session of speed endurance training, where peak blood lactate (14.5$16.5 \mathrm{mmoll}^{-1}$ ) and plasma $\mathrm{K}^{+}$(about $6.4 \mathrm{mmoll}^{-1}$ ) were higher compared to the sprint training responses (blood lactate: $\sim 8.5$ and $\mathrm{K}^{+}: \sim 5.5 \mathrm{mmoll}^{-1}$ ).

The marked increases in extracellular $\mathrm{K}^{+}$that are commonly observed during high-intensity exercise contribute to muscle fatigue by causing depolarization of the sarcolemmal and t-tubular membranes (McKenna et al., 2008). A training-induced increase in $\mathrm{Na}-\mathrm{K}^{+}$ATPase activity has been shown to contribute to the control of $\mathrm{K}^{+}$homeostasis and reduce fatigue (Mohr et al., 2007).

However, the importance of $\mathrm{pH}$ regulation, especially in less trained and non-athletic populations and patients with various diseases should not be overlooked. It is well established that the $\mathrm{pH}$ regulating systems in skeletal muscles are very responsive to HIT (Juel, 2008). During high-intensity exercise and the subsequent recovery period, muscle $\mathrm{pH}$ is regulated by three systems: (1) lactate $/ \mathrm{H}^{+}$co-transport by two important monocarboxylate transporter proteins: MCT1 and MCT4, (2) $\mathrm{Na}^{+} / \mathrm{H}^{+}$exchange by a specific exchanger protein, and $(3) \mathrm{Na}^{+}$/bicarbonate transporters (Juel, 2008). The MCT1 and MCT4 transporters are considered as the most important during exercise and thus their changes following training have been extensively studied in animal and human muscle. Animal studies have shown that HIT in rats for 5 weeks results in 30 and $85 \%$ in the MCT1 and $\mathrm{Na}^{+} /$bicarbonate transporter, respectively, while MCT4 remained unchanged (Thomas et al., 2007). In humans, changes in the $\mathrm{Na}^{+} / \mathrm{H}^{+}$exchanger protein levels by $30 \%$ have been reported in the 4 -week high-intensity sprint training study of Iaia et al. (2008). Moreover, significant increases in MCT1 and $\mathrm{Na}^{+} / \mathrm{H}^{+}$exchanger protein densities have been found after HIT, especially when training bouts cause a significant accumulation of $\mathrm{H}^{+}$in the muscle (Mohr et al., 2007). Increased expression of lactate and $\mathrm{H}^{+}$transporters results in faster $\mathrm{H}^{+}$and lactate release. Juel et al. (2004) used the one-legged knee extensor exercise model to examine changes in muscle $\mathrm{pH}$ regulating systems following intense training. Following 7 weeks of training with $15 \times 1 \mathrm{~min}$ bouts of single knee extensions at $150 \%$ $V_{\mathrm{O}_{2}}$ max per day, time to exhaustion was improved by $29 \%$. The rate of lactate release at exhaustion was almost double $(19.4 \pm 3.6$ vs. $\left.10.6 \pm 2.0 \mathrm{mmol} \mathrm{min}^{-1}, \mathrm{P}<0.05\right)$ and the rate of $\mathrm{H}^{+}$release was $\sim 50 \%$ higher $\left(36.9 \pm 3.1\right.$ vs. $\left.24.2 \pm 1.5 \mathrm{mmol} \mathrm{min}^{-1}, P<0.05\right)$ for the trained than for the untrained leg. The membrane contents of the MCT1 lactate $/ \mathrm{H}^{+}$co-transporter and $\mathrm{Na}^{+} / \mathrm{H}^{+}$exchanger proteins were increased by 15 and $16 \%$, while blood flow was also increased by $16 \%$ in the trained compared to the untrained leg. This study demonstrated that when muscle is stressed with training stimuli that cause high intramuscular lactate and $\mathrm{H}^{+}$concentration, it adapts by increasing the rate of lactate and $\mathrm{H}^{+}$transport out of the muscle. These adaptations are done by both changes in specific membrane proteins and structural changes, such as increased capillary density (Jensen et al., 2004), that enhance blood flow and thus transport of lactate and $\mathrm{H}^{+}$away from the working muscle.

Within the muscle cell, the ability to buffer the build-up of free $\mathrm{H}^{+}$in the muscle during high-intensity exercise is an important determinant of fatigue resistance and may be improved by training. To test this hypothesis, Edge et al. (2006) trained recreationally active female team sport players for 3 days per week for 5 weeks, using two protocols with matched for total work but different intensity. The high-intensity group performed six to ten 2 -min bouts of cycling with $1 \mathrm{~min}$ rest at an intensity that was $120-140 \%$ of that corresponding to the $4-\mathrm{mmol}^{-1}$ blood lactate threshold. The moderate-intensity group performed continuous exercise at $80-95 \%$ of that corresponding to the lactate threshold for 20-30 min, so that the total work was the same with the high-intensity group. Blood lactate at the end of a typical training session was $16.1 \pm 4.0 \mathrm{mmoll}^{-1}$ for the high-intensity group and only $5.1 \pm 3.0 \mathrm{mmoll}^{-1}$ for the moderate-intensity exercise group. $V_{\mathrm{O}_{2}}$ max and the intensity corresponding to lactate threshold were equally improved (by 10-14\%) in both groups, but only the high-intensity group showed a significant increase in buffering capacity by $25 \%$ (from $123 \pm 5$ to $153 \pm 7 \mu \mathrm{mol} \mathrm{H}{ }^{+}$g dry muscle $\left.{ }^{-1} \mathrm{pH}^{-1}, P<0.05\right)$, coupled with a greater improvement in a repeated sprint exercise performance compared with the low intensity group ( 13.0 vs. $8.5 \%, P<0.05$, Edge et al., 2005). Taken collectively, the above results emphasize the importance of exercise intensity for achieving the most favorable adaptations that delay muscle acidification and increase fatigue resistance. A reduced rate of $\mathrm{H}^{+}$accumulation, by transporting more $\mathrm{H}^{+}$out of the muscle and/or by intracellular buffering, would allow a greater contribution of glycolysis to energy supply and thus higher muscle performance.

\section{EFFECTS OF PHYSICAL INACTIVITY ON MUSCLE FATIGUE DETRAINING}

Detraining is a period of insufficient or reduced training stimulus that causes reversal of adaptations at rates depending on the magnitude of physical activity reduction and by the length of the deconditioning period. Muscular and neural adaptations may be reversed at different rates, while muscle fiber phenotype is altered toward an increased expression of the fast MHC IIX phenotype (Andersen and Aagaard, 2000).

A common practice in detraining studies is to train the participants for a short or longer period and then remove the training stimulus and measure the detraining adaptations. Andersen et al. (2005) trained sedentary young males using knee extension exercises three times per week for 3 months using moderate to heavy resistances (from 10 to 6 repetition maximum, $\mathrm{RM})$. Testing was performed before the start of training, after 3 months of training and again 3 months after detraining. Following 3 months of training, the CSA of quadriceps and EMG activity both increased by $10 \%$. Also, isokinetic muscle strength at 30 and $240^{\circ} \mathrm{s}^{-1}$, was increased by $18 \%(P<0.01)$ and $10 \%(P<0.05)$, but power, velocity, and acceleration of unloaded knee extension was unchanged. The proportion of MHC IIX decreased from $5.6 \pm 0.8$ to $0.8 \pm 0.3 \%(P<0.001)$, with a corresponding increase of MHC 
IIA proportion from $34.0 \pm 2.5$ to $39.4 \pm 2.0 \%(P<0.001)$. After 3 months of detraining isokinetic CSA, EMG and muscle strength and power at 30 and $240^{\circ} \mathrm{s}^{-1}$ returned to pre-training levels. However, unloaded knee extension angular velocity and power were increased remarkably by 14 and $44 \%$ in relation to pre and post training. This was accompanied by an increase in MHC IIX isoform from $0.8 \pm 0.3$ to $7.7 \pm 1.1 \%$, which was significantly higher compared with both pre and post training levels $(P<0.001)$. This phenomenon, i.e., an increase of the fast MHC IIX isoform is a typical adaptation to detraining following systematic training and has been observed in even greater extent (from $2.0 \pm 0.8$ to $17.2 \pm 3.2 \%, P<0.01)$, after a similar protocol of training and detraining (Andersen and Aagaard, 2000). However, this is accompanied by a reduction in type II fiber CSA, which would actually make the muscle weaker when higher loads than only the weight of the limb are to be moved (e.g., body weight).

From a metabolic point of view, detraining results in a marked decrease in muscle oxidative capacity, as indicated by a large decrease in mitochondrial enzyme activities. In the 10-week training study of Linossier et al. (1997) presented earlier in this review, the increased activities of the glycolytic enzymes were not reversed after 7 weeks of detraining. However, $V_{\mathrm{O}_{2}} \max$ and oxidative enzymes (CS and HAD) were decreased at or below the pre-training values. Simoneau et al. (1987) reported similar results of no significant change in glycolytic enzymes, but a significant reduction of oxidative enzymes after 7 weeks of detraining. In a more recent study (Burgomaster et al., 2007), cytochrome $c$ oxidase subunit, a marker of oxidative capacity, remained elevated even after 6 weeks of detraining following 6 weeks of HIT. However, some studies have reported decreases in glycolytic enzymes in highly trained athletes who stop training for 4-8 weeks (Mujika and Padilla, 2001).

As discussed earlier in the review, exercise-induced angiogenesis (increased capillarization) is an important adaptation to HIT that is possibly mediated by the increased expression of PGC$1 \alpha$ (Tadaishi et al., 2011). Earlier studies reported that a short period of detraining does not seem to significantly decrease capillary density of the previously trained muscle, possibly due to the concomitant decrease in muscle fiber area (Klausen et al., 1981; Coyle et al., 1984). However, more recent data suggest that only a short period of detraining is adequate to reverse training-induced angiogenic remodeling, as seen by the regression of capillary contacts and individual capillary-to-fiber ratio in the plantaris and soleus muscles of rats (Malek et al., 2010). These authors suggested that this was modulated by vascular endothelial growth factor (VEGF).

The reductions in oxidative enzyme activities together with the shifting of muscle fiber type to the fast fatigable MHC IIX isoform would increase fatigue during high-intensity exercise following a period of detraining. However, short ( $\sim 2$ week) "tapering" period of decreased training volume (by 40-60\%) without changes in training intensity and frequency is commonly used by athletes to maximize performance gains (Bosquet et al., 2007). This short period of reduced training volume, would take advantage of the positive adaptations of detraining, while at the same time would avoid the negative long term effects of reduced activity.

\section{IMMOBILIZATION AND DISUSE}

Athletes and physically active individuals may be forced to short term immobilization of a limb or even to bed rest due to acute injury or illness. The consequences of gravitational unloading have been extensively investigated in recent years (Ohira et al., 2002; Urso, 2009). One of the most typical adaptations to immobilization is muscle atrophy, accompanied with decreases in functional capacity. Antigravity muscles (e.g., gastrocnemius and soleus) are most susceptible to atrophy following bed rest (Clark, 2009). The loss of muscle strength during a period of 4-6 weeks of unloading has been largely attributed to the loss of contractile proteins (Degens and Always, 2006; Urso, 2009), but it exceeds the loss of muscle mass due to neurological factors (Clark, 2009). Disuseinduced deficits in central activation may account for about $50 \%$ of the between - person variability in the loss of knee extensor strength after 3 weeks of bed rest (Kawakami et al., 2001). Deschenes et al. (2002) hypothesized that the loss of strength resulting from a 2 -week unilateral lower limb unloading, was due to impaired neural activation of the affected muscle. In that study they immobilized the lower limb of healthy young college students in a light weight orthopedic knee brace at an angle of $70^{\circ}$, with the purpose to eliminate weight bearing activity. After 2 weeks of immobilization, peak isokinetic torque of the knee extensors across a range of velocities was reduced by an average of $17.2 \%$ with greater losses in slow than in fast contraction velocities. The reduction in torque was coupled by reduced EMG activity, but the ratio of total torque/EMG was unchanged. Muscle fiber composition remained unchanged in the 2 -week unloading period.

Studies performed using animal models of hindlimb unloading showed that there is a shift of MHC isoforms from slow to fast, accompanied by significant muscle atrophy (Leterme and Falempin, 1994; Picquet and Falempin, 2003). It is noteworthy that chronic electrostimulation prevented the shift in fiber types, but failed to counteract the loss of muscle mass and force output (Leterme and Falempin, 1994). Similarly, tendon vibration applied daily on the unloaded hindlimb significantly attenuated, but did not prevent the loss of muscle mass and the changes in fiber type (Falempin and In-Albon, 1999).

A decrease in capillary supply and blood flow during rest and exercise is common in unloaded muscle. Degens and Always (2006) reported that the capillary loss and reduction in maximal blood flow are largely proportional to the loss of muscle mass, maintaining blood flow per unit muscle mass. However, a recent investigation looking at the effects of a 9-day hind limb unloading on both capillarization and expression of angio-adaptive molecules reported differences in capillary regression between fast and slow rat skeletal muscles (Roudier et al., 2010). In that experiment, both soleus and plantaris muscles were atrophied similarly, but capillary regression occurred only in the soleus, which is a slow twitch and oxidative postural muscle. Conversely, capillarization was preserved in the plantaris, a fast twitch, glycolytic muscle. The authors reported that the key pro- and anti-angiogenic signals (various types of VEGF) play a determinant role in regulating this process.

The muscle fatigue profile following muscle disuse atrophy involve both the loss of strength, transition from slow to fast myosin, a shift toward glycolysis and a decreased capacity for fat 
oxidation (Stein and Wade, 2005). However, caution should be exercised when measuring fatigue on a disused muscle. In the immobilization study of Deschenes et al. (2002), fatigue resistance was assessed during a 30 repetition set of isokinetic knee extensions at $3.14 \mathrm{rads}^{-1}$, as the difference in total work produced during the first 10 repetitions compared with the last 10 repetitions. By calculating this percent decrease of work, fatigue resistance was enhanced instead of decreased following immobilization (drop in total work $29.8 \pm 2.5$ vs. $20.6 \pm 6.5 \%$, pre vs. post immobilization; $P<0.05)$. However, the total work generated over the 30 contractions was $15 \%$ less after immobilization $(2735.3 \pm 207.6$ vs. $2339.0 \pm 163.3 \mathrm{~J}, P<0.05)$. This artifact, i.e., an improvement rather than a reduction of fatigue resistance should be interpreted with caution because this is simply due to the lower total work in the first 10 repetitions after immobilization.

The length of immobilization plays an important role in the negative adaptations resulting from muscle unloading. When immobilization is longer than 4 weeks, there is a large increase in fatigability linked with reductions in oxidative capacity due to decreases in CS and PDH. Indeed, Ward et al. (1986), showed that after 5 weeks of immobilization, the proportion of PDH in the active form was only 52\%, compared with $98 \%$ after training 5 months training. This results in greater lactate and $\mathrm{H}^{+}$ accumulation during exercise after the immobilization period.

\section{USE OF HIGH-INTENSITY INTERMITTENT EXERCISE TRAINING IN PATIENT POPULATIONS}

Many chronic diseases, such as coronary artery disease (CAD), COPD result in a progressively reduced exercise capacity due to both biochemical and morphological changes in skeletal muscles. Abnormal fiber-type proportions have been found in COPD patients, with markedly lower type I oxidative fibers (16 vs. 42\%) compared to controls (Gosker et al., 2002). Also, oxidative capacity of type I, as well as of type IIA fibers was lower than normal, thus making those patients more susceptible to peripheral muscle fatigue. The reduced exercise capacity and increased muscle fatigue of those patients is not only due to intolerable sensations of breathlessness, but also due to peripheral muscle discomfort (Vogiatzis, 2011). The inability of those patients to be physically active reduces even more their exercise capacity and this vicious circle increases the risk of negative health outcomes due to the sedentary lifestyle (Rimmer et al., 2012). COPD patients have a reduced tolerance of continuous exercise and different rehabilitative strategies and training modalities have been proposed to optimize exercise tolerance. Several recent investigations have shown that the greater physiological benefits can be obtained through high-intensity intermittent, compared with moderateintensity continuous training. Vogiatzis (2011) has shown that using interval exercise in the form of $30 \mathrm{~s}$ on and $30 \mathrm{~s}$ off, at an intensity of $100 \%$ of maximum work rate, COPD patients can almost triple the total exercise duration (30 vs. $12 \mathrm{~min}$ ), with significantly lower and more stable metabolic and ventilator responses compared with continuous exercise. Patients with severe COPD can endure high-intensity interval training in a rehabilitation setting for long periods of time with lower symptoms of dyspnea and leg discomfort compared with the conventionally implemented continuous training (Kortianou et al., 2010). This is due to the beneficial effects of the recovery intervals that allow PCr resynthesis and lactate removal. The increased availability of PCr in each short exercise bout and its short-duration result in a decreased reliance on anaerobic glycolysis that results in less lactate accumulation and allows more intense exercise stimuli to the peripheral muscle with less cardiac and respiratory strain. A recent study showed that this type of training performed by severe COPD patients allowed them to exercise at a sufficiently high intensity to obtain true physiological training effects manifested by improvements in muscle fiber size, type, and capillarization (Vogiatzis et al., 2011).

High-intensity interval training in the form of four repeated 4 min bouts at $90-95 \%$ of peak heart rate, separated by $2-3 \mathrm{~min}$ or active recovery at $\sim 60-70 \%$ of peak heart rate, has been used successfully in cardiac patients (Wisloff et al., 2009). In those patients fatigue occurs not only because of reduced cardiac function but also due to skeletal muscle fatigue (Downing and Balady, 2011). Decreased muscle mass and capillarization, shifting of slow to fast-twitch fibers that rely more on glycolysis, as well as reduced mitochondrial size and oxidative enzymes are typically found in heart failure patients and cannot be explained by deconditioning alone (Downing and Balady, 2011). The role of inflammatory mediators, such as tumor necrosis factor and interleukin- 6 , in the pathogenesis of skeletal muscle wasting and fatigue in numerous clinical settings including heart failure, is an area of active investigation. Interestingly, inflammatory cytokines are reduced following exercise training, in parallel with the improved fatigue resistance (Downing and Balady, 2011). Supervised high-intensity intermittent training can be safely prescribed as a time-efficient strategy in those patients because it results in far superior adaptations compared with conventional low intensity exercise training (Moholdt et al., 2012). This type of exercise not only reduces muscle fatigue but also improves cardiorespiratory fitness, endothelial function, left ventricle morphology and function (e.g., ejection fraction) in all cardiac patients, with no adverse or other lifethreatening events occurring secondary to exercise participation (Cornish et al., 2011).

This type of aerobic interval training has also been used for the treatment of metabolic syndrome (Tjonna et al., 2008). Patients exercised three times per week for 16 weeks and compared to the traditional low intensity training group, the high-intensity exercise group demonstrated a larger improvement in $V_{\mathrm{O}_{2} \text { max }}$ (35 vs. $16 \%, P<0.01$ ), endothelial function ( 9 vs. $5 \%, P<0.001$ ), insulin signaling in fat and skeletal muscle, fasting blood glucose, and lipogenesis in adipose tissue. Furthermore, both the continuous and the intermittent exercise programs were equally effective in reducing mean arterial blood pressure and body weight and fat.

The use of high-intensity interval training in the form of short cycle ergometer sprints lasting 10-20 s has been recently used as a time-efficient alternative to traditional cardiorespiratory training with a target to improve metabolic health (Metcalfe et al., 2011). The subjects were healthy but sedentary men and women who trained three times per week for 6 weeks, with sessions lasting only 10 min, including only one or two 10-20 s sprints and a warm-up and cool-down. Insulin sensitivity in the male training group was increased by $28 \%$, while $V_{\mathrm{O}_{2}}$ peak was increased by 15 and $12 \%$ in the males and females, respectively. 


\section{CONCLUSION AND FUTURE PERSPECTIVES}

Muscle fatigue is not only important for sports settings but may be vital during everyday life because it may pose a barrier to normal physical activity. Deconditioning due to sedentary lifestyle and/or cardiovascular and pulmonary diseases may limit exercise capacity and increase fatigability, resulting in further deterioration of health and well being. However, the adverse effects of physical inactivity can be reversed by exercise training and the extended use of high-intensity interval training

\section{REFERENCES}

Allen, D., Lamb, G. D., and Westerblad, H. (2008). Skeletal muscle fatigue: cellular mechanisms. Physiol. Rev. $88,287-332$.

Amann, M., and Dempsey, J. A. (2008). Locomotor muscle fatigue modifies central motor drive in healthy humans and imposes a limitation to exercise performance. J. Physiol. (Lond.) 586, 161-173.

Andersen, J. L., and Aagaard, P. (2000). Myosin heavy chain IIX overshoot in human skeletal muscle. Muscle Nerve 2, 1095-1104.

Andersen, J. L., and Aagaard, P. (2010). Effects of strength training on muscle fiber types and size; consequences for athletes training for high-intensity sport. Scand. J. Med. Sci. Sports 20(Suppl. 2), 32-38.

Andersen, J. L., Klitgaard, H., and Saltin, B. (1994). Myosin heavy chain isoforms in single fibres from $m$. vastus lateralis of sprinters: influence of training. Acta Physiol. Scand. 151, 135-142.

Andersen, L. L., Andersen, J. L., Magnusson, S. P., Suetta, C., Madsen, J. L., Christensen, L. R., and Aagaard, P. (2005). Changes in the human muscle force-velocity relationship in response to resistance training and subsequent detraining. J. Appl. Physiol. 99, 87-94.

Andersen, P., and Henriksson, J. (1977). Capillary supply of the quadriceps femoris muscle of man: adaptive response to exercise. J. Physiol. (Lond.) 270, 677-690.

Astorino, T. A., Allen, R. P., Roberson, D. W., and Jurancich, M. (2012). Effect of high-intensity interval training on cardiovascular function, $\mathrm{VO} 2 \mathrm{max}$, and muscular force. J. Strength Cond. Res. 26, 138-145.

Barnett, C., Carey, M., Proietto, J., Cerin, E., Febbraio, M. A., and Jenkins, D. (2004). Muscle metabolism during sprint exercise in man: influence of sprint training. J. Sci. Med. Sport 7, 314-22.

Behm, D. G., Whittle, J., Button, D., and Power, K. (2002). Intermuscle differences in activation. Muscle Nerve 25, 236-243.
Bigland-Ritchie, B., Cafarelli, E., and Vøllestad, N. K. (1986). Fatigue of submaximal static contractions. Acta Physiol. Scand. 556, 137-148.

Billaut, F., Basset, F. A., Giacomoni, M., Lemaitre, F., Tricot, V., and Falgairette, G. (2006). Effect of highintensity intermittent cycling sprints on neuromuscular activity. Int. J. Sports Med. 27, 25-30.

Bishop, D., and Edge, J. (2006). Determinants of repeated-sprint ability in females matched for single-sprint performance. Eur. J. Appl. Physiol. 97, 373-379.

Bishop, D., Girard, O., and Mendezsprint ability - part II: recommendations for training. Sports Med. 41, 741-756.

Bishop, D., Lawrence, S., and Spencer, M. (2003) Predictors of repeatedsprint ability in elite female hockey players. J. Sci. Med. Sport 6, 199-209.

Bishop, D., and Spencer, M. (2004). Determinants of repeated-sprint ability in well-trained team-sport athletes and endurance-trained athletes. J. Sports Med. Phys. Fitness 44, $1-7$.

Bloomfield, S. A. (1997). Changes in musculoskeletal structure and function with prolonged bed rest. Med. Sci. Sports Exerc. 29, 197-206.

Bogdanis, G. C., Nevill, M. E., Boobis, L. H., and Lakomy, H. K. (1996). Contribution of phosphocreatine and aerobic metabolism to energy supply during repeated sprint exercise. J. Appl. Physiol. 80, 876-884.

Bogdanis, G. C., Nevill, M. E., Boobis, L. H., Lakomy, H. K., and Nevill, A. M. (1995). Recovery of power output and muscle metabolites following $30 \mathrm{~s}$ of maximal sprint cycling in man. J. Physiol. (Lond.) 482, 467-480.

Bogdanis, G. C., Nevill, M. E., Lakomy, H. K., and Boobis, L. H. (1998). Power output and muscle metabolism during and following recovery from 10 and $20 \mathrm{~s}$ of maximal sprint exercise in humans. Acta Physiol. Scand. 163, 261-272.

Bosquet, L., Montpetit, J., Arvisais, D., and Mujika, I. (2007). Effects of Villanueva, A. (2011). Repeated-

as a time-efficient strategy for improving both sports performance and health-related fitness requires further investigation. Since exercise intensity and duration are key variables for adaptations, more research is needed to reveal the best combination of those variables for each population group. Also, the safety of this type of training in the short and longer term and the possibility of overtraining should be examined in larger patient cohorts as well as in different age groups of healthy individuals.

tapering on performance: a metaanalysis. Med. Sci. Sports Exerc. 39, 1358-1365.

Bottinelli, R. (2001). Functional heterogeneity of mammalian single muscle fibres: do myosin isoforms tell the whole story? Pflugers Arch. 443, 6-17. Burgomaster, K. A., Cermak, N. M. Phillips, S. M., Benton, C. R., Bonen, A., and Gibala, M. J. (2007). Divergent response of metabolite transport proteins in human skeletal muscle after sprint interval training and detraining. Am. J. Physiol. 292, R1970-R1976.

Burgomaster, K. A., Heigenhauser, G. J., and Gibala, M. J. (2006). Effect of short-term sprint interval training on human skeletal muscle carbohydrate metabolism during exercise and time-trial performance. J. Appl. Physiol. 100, 2041-2047.

Burgomaster, K. A., Howarth, K. R., Phillips, S. M., Rakobowchuk, M., Macdonald, M. J., McGee, S. L., and Gibala, M. J. (2008). Similar metabolic adaptations during exercise after low volume sprint interval and traditional endurance training in humans. J. Physiol. (Lond.) 586 151-160.

Burgomaster, K. A., Hughes, S. C., Heigenhauser, G. J., Bradwell, S. N., and Gibala, M. J. (2005). Six sessions of sprint interval training increases muscle oxidative potential and cycle endurance capacity in humans. J. Appl. Physiol. 98, 1985-1990.

Cairns, S. P., and Lindinger, M. I. (2008). Do multiple ionic interactions contribute to skeletal muscle fatigue? J. Physiol. (Lond.) 586, 4039-4054.

Calbet, J. A., De Paz, J. A., Garatachea, N., Cabeza de Vaca, S., and Chavarren, J. (2003). Anaerobic energy provision does not limit Wingate exercise performance in endurancetrained cyclists. J. Appl. Physiol. 94, 668-676.

Calvo, J. A., Daniels, T. G., Wang, X., Paul, A., Lin, J., Spiegelman, B. M., Stevenson, S. C., and Rangwala, S. M. (2008). Muscle-specific expression of PPARgamma coactivator-1alpha improves exercise performance and increases peak oxygen uptake. J. Appl. Physiol. 104, 1304-1312.

Casey, A., Constantin-Teodosiu, D., Howell, S., Hultman, E., and Greenhaff, P. L. (1996). Metabolic response of type I and II muscle fibres during repeated bouts of maximal exercise in humans. Am. J. Physiol. 271, E38-E43.

Clark, B. C. (2009). In vivo alterations in skeletal muscle form and function after disuse atrophy. Med. Sci. Sports Exerc. 41, 1869-1875.

Coffey, V. G., and Hawley, J. A. (2007). The molecular bases of training adaptation. Sports Med. 37, 737-763.

Colliander, E. B., Dudley, G. A., and Tesch, P. A. (1988). Skeletal muscle fibre type composition and performance during repeated bouts of maximal, concentric contractions. Eur. J. Appl. Physiol. 58, 81-86.

Cooke, S. R., Petersen, S. R., and Quinney, H. A. (1997). The influence of maximal aerobic power on recovery of skeletal muscle following anaerobic exercise. Eur. J. Appl. Physiol. 75, 512-519.

Cornish, A. K., Broadbent, S., and Cheema, B. S. (2011). Interval training for patients with coronary artery disease: a systematic review. Eur. J. Appl. Physiol. 111, 579-589.

Costill, D. L., Daniels, J., Evans, W., Fink, W., Krahenbuhl, G., and Saltin, B. (1976). Skeletal muscle enzymes and fibre composition in male and female track athletes. J. Appl. Physiol. 40, 149-154.

Coyle, E. F. (2005). Very intense exercise-training is extremely potent and time efficient: a reminder. J. Appl. Physiol. 98, 1983-1984.

Coyle, E. F., Coggan, A. R., Hopper, M. K., and Walters, T. J. (1988). Determinants of endurance in welltrained cyclists. J. Appl. Physiol. 64, 2622-2630.

Coyle, E. F., Martin, W. H. III, Sinacore, D. R., Joyner, M. J., Hagberg, J. M., and Holloszy, J. O. (1984) Time course of loss of adaptations after stopping prolonged intense endurance training. J. Appl. Physiol. 57, 1857-1864. 
D’Antona, G., Lanfranconi, F., Pellegrino, M. A., Brocca, L., Adami, R., Rossi, R., Moro, G., Miotti, D., Canepari, M., and Bottinelli, R. (2006). Skeletal muscle hypertrophy and structure and function of skeletal muscle fibres in male body builders. J. Physiol. (Lond.) 570, 611-627.

Dawson, B., Fitzsimons, M., Green, S., Goodman, C., Carey, M., and Cole, K. (1998). Changes in performance, muscle metabolites, enzymes and fibre types after short sprint training. Eur. J. Appl. Physiol. 78, 163-169.

Degens, H., and Always, S. E. (2006). Control of muscle size during disuse, disease, and aging. Int. J. Sports Med. 27, 94-99.

Deschenes, M. R., Giles, J. A., McCoy, R. W., Volek, J. S., Gomez, A. L., and Kraemer, W. J. (2002). Neural factors account for strength decrements observed after short-term muscle unloading. Am. J. Physiol. 282, R578-R583.

Downing, J., and Balady, G. J. (2011). The role of exercise training in heart failure. J. Am. Coll. Cardiol. 58, 561-569.

Dudley, G. A., Abraham, W. M., and Terjung, R. L. (1982). Influence of exercise intensity and duration on biochemical adaptations in skeletal muscle. J. Appl. Physiol. 53, 844-850.

Dupont, G., Millet, G. P., Guinhouya, C., and Berthoin, S. (2005). Relationship between oxygen uptake kinetics and performance in repeated running sprints. Eur. J. Appl. Physiol. 95, 27-34.

Edge, J., Bishop, D., and Goodman, C. (2006). The effects of training intensity on muscle buffer capacity in females. Eur. J. Appl. Physiol. 96, 97-105.

Edge, J., Bishop, D., Goodman, C., and Dawson, B. (2005). Effects of high- and moderate-intensity training on metabolism and repeated sprints. Med. Sci. Sports Exerc. 37, 1975-1982.

Edwards, R. H. (1981). "Human muscle function and fatigue," in Human Muscle Fatigue: Physiological Mechanisms, eds R. Porter and J. Whelan (London: Pitman Medical), 1-18.

Esbjörnsson, M., Hellsten-Westing, Y., Balsom, P. D., Sjödin, B., and Jansson, E. (1993). Muscle fibre type changes with sprint training: effect of training pattern. Acta Physiol. Scand. 149, 245-246.

Falempin, M., and In-Albon, S. F. (1999). Influence of brief daily tendon vibration on rat soleus muscle in non-weight-bearing situation. $J$. Appl. Physiol. 87, 3-9.
Ferrari Bravo, D., Impellizzeri, F. M., Rampinini, E., Castagna, C., Bishop, D., and Wisloff, U. (2008). Sprint vs. interval training in football. Int. J. Sports Med. 29, 668-674.

Ferreira, L. F., and Reid, M. B. (2008). Muscle-derived ROS and thiol regulation in muscle fatigue. J. Appl. Physiol. 104, 853-860.

Fitts, R. H. (1994). Cellular mechanisms of muscle fatigue. Physiol. Rev. 74, 49-94.

Fitts, R. H. (2003). Effects of regular exercise training on skeletal muscle contractile function. Am. J. Phys. Med. Rehabil. 82, 320-331.

Fitts, R. H. (2008). The cross-bridge cycle and skeletal muscle fatigue. $J$. Appl. Physiol. 104, 551-558.

Fitts, R. H., and Widrick, J. J. (1996). Muscle mechanics: adaptations with exercise-training. Exerc. Sport Sci. Rev. 24, 427-473.

Fitzsimons, M., Dawson, B., Ward, D., and Wilkinson, A. (1993). Cycling and running tests of repeated sprint ability. Aust. J. Sci. Med. Sport 25, 82-87.

Gaitanos, G. C., Williams, C., Boobis, L. H., and Brooks, S. (1993). Human muscle metabolism during intermittent maximal exercise. J. Appl. Physiol. 75, 712-719.

Garrandes, F., Colson, S. S., Pensini, M., Seynnes, O., and Legros, P. (2007). Neuromuscular fatigue profile in endurance-trained and powertrained athletes. Med. Sci. Sports Exerc. 39, 149-158.

Gibala, M. J. (2009). Molecular responses to high-intensity interval exercise. Appl. Physiol. Nutr. Metab. 34, 428-432.

Gibala, M. J., Little, J. P., Macdonald, M. J., and Hawley, J. A. (2012). Physiological adaptations to low-volume, high-intensity interval training in health and disease. J. Physiol. (Lond.) 590, 1077-1084.

Gibala, M. J., Little, J. P., van Essen, M., Wilkin, G. P., Burgomaster, K. A., Safdar, A., Raha, S., and Tarnopolsky, M. A. (2006). Shortterm sprint interval versus traditional endurance training: similar initial adaptations in human skeletal muscle and exercise performance. $J$. Physiol. (Lond.) 575, 901-911.

Girard, O., Mendez-Villanueva, A., and Bishop, D. (2011). Repeated-sprint ability - part I: factors contributing to fatigue. Sports Med. 41, 673-694.

Gosker, H. R., van Mameren, H., van Dijk, P. J., Engelen, M. P., van der Vusse, G. J., Wouters, E. F., and Schols, A. M. (2002). Skeletal muscle fibre-type shifting and metabolic profile in patients with chronic obstructive pulmonary disease. Eur. Respir. J. 19, 617-625.

Green, H. J., and Pette, D. (1997). Early metabolic adaptations of rabbit fast-twitch muscle to chronic low-frequency stimulation. Eur. J. Appl. Physiol. 75, 418-424.

Greenhaff, P. L., Nevill, M. E., Soderlund, K., Bodin, K., Boobis, L. H., Williams, C., and Hultman, E. (1994). The metabolic responses of human type I and II muscle fibres during maximal treadmill sprinting. J. Physiol. (Lond.) 478, 149-155.

Hamada, T., Sale, D. G., MacDougall, J. D., and Tarnopolsky, M. A. (2003). Interaction of fibre type, potentiation and fatigue in human knee extensor muscles. Acta Physiol. Scand. 178, 165-173.

Hamilton, A. L., Nevill, M. E. Brooks, S., and Williams, C. (1991). Physiological responses to maximal intermittent exercise: differences between endurance-trained runners and games players. J. Sports Sci. 9, 371-382.

Harber, M., and Trappe, S. (2008). Single muscle fiber contractile properties of young competitive distance runners. J. Appl. Physiol. 105, 629-636.

Harridge, S. D., Bottinelli, R., Canepari, M., Pellegrino, M., Reggiani, C., Esbjornsson, M., Balsom, P. D., and Saltin, B. (1998). Sprint training, in vitro and in vivo muscle function, and myosin heavy chain expression. J. Appl. Physiol. 84, 442-449.

Haseler, L. J., Hogan, M. C., and Richardson, R. S. (1999). Skeletal muscle phosphocreatine recovery in exercise-trained humans is dependent on $\mathrm{O} 2$ availability. J. Appl. Physiol. 86, 2013-2018.

Haseler, L. J., Lin, A., Hoff, J., and Richardson, R. S. (2007). Oxygen availability and $\mathrm{PCr}$ recovery rate in untrained human calf muscle: evidence of metabolic limitation in normoxia. Am. J. Physiol. 293, R2046R2051.

Haseler, L. J., Lin, A. P., and Richardson, R. S. (2004). Skeletal muscle oxidative metabolism in sedentary humans: 31P-MRS assessment of $\mathrm{O} 2$ supply and demand limitations. J. Appl. Physiol. 97, 1077-1081.

Hautier, C. A., Arsac, L. M., Deghdegh, K., Souquet, J., Belli, A., and Lacour, J. R. (2000). Influence of fatigue on EMG/force ratio and cocontraction in cycling. Med. Sci. Sports Exerc. 32, 839-843.

Helgerud, J., Engen, L. C., Wisloff, U., and Hoff, J. (2001). Aerobic endurance training improves soccer performance. Med. Sci. Sports Exerc. 33, 1925-1931.

Hernandez, A., Cheng, A., and Westerblad, H. (2012). Antioxidants and skeletal muscle performance: "common knowledge" vs. experimental evidence. Front. Physiol. 3:46. doi:10.3389/fphys.2012.00046

Hurley, B. F., Hanson, E. D., and Sheaff, A. K. (2011). Strength training as a countermeasure to aging muscle and chronic disease. Sports Med. 41, 289-306.

Iaia, F. M., and Bangsbo, J. (2010). Speed endurance training is a powerful stimulus for physiological adaptations and performance improvements of athletes. Scand. J. Med. Sci. Sports 20, 11-23.

Iaia, F. M., Thomassen, M., Kolding, H., Gunnarsson, T., Wendell, J., Rostgaard, T., Nordsborg, N., Krustrup, P., Nybo, L., Hellsten, Y., and Bangsbo, J. (2008). Reduced volume but increased training intensity elevates muscle $\mathrm{Na}^{+}-\mathrm{K}^{+}$pump $\alpha 1$-subunit and NHE1 expression as well as short-term work capacity in humans. Am. J. Physiol. 294, R966-R974.

Jensen, L., Bangsbo, J., and Hellsten, Y. (2004). Effect of high intensity training on capillarization and presence of angiogenic factors in human skeletal muscle. J. Physiol. (Lond.) 557, 571-582.

Johansen, L., and Quistorff, B. (2003). 31P-MRS characterization of sprint and endurance trained athletes. Int. J. Sports Med. 24, 183-189.

Juel, C. (2008). Regulation of $\mathrm{pH}$ in human skeletal muscle: adaptations to physical activity. Acta Physiol. (Oxf.) 193, 17-24.

Juel, C., Klarskov, C., Nielsen, J. J., Krustrup, P., Mohr, M., and Bangsbo, J. (2004). Effect of high-intensity intermittent training on lactate and $\mathrm{H}^{+}$release from human skeletal muscle. Am. J. Physiol. 286, E245E251.

Karatzaferi, C., de Haan, A., Ferguson, R. A., van Mechelen, W., and Sargeant, A. J. (2001a). Phosphocreatine and ATP content in human single muscle fibres before and after maximum dynamic exercise. Pflugers Arch. 442, 467-474.

Karatzaferi, C., de Haan, A., van Mechelen, W., and Sargeant, A. J. (2001b) Metabolic changes in single human fibres during brief maximal exercise. Exp. Physiol. 86, 411-415.

Kawakami, Y., Akima, H., Kubo, K., Muraoka, Y., Hasegawa, H., Kouzaki, M., Imai, M., Suzuki, Y., Gunji, A., Kanehisa, H., and Fukunaga, T. (2001). Changes in muscle size, 
architecture, and neural activation after 20 days of bed rest with and without resistance exercise. Eur. J. Appl. Physiol. 84, 7-12.

Klausen, K., Andersen, L. B., and Pelle, I. (1981). Adaptive changes in work capacity, skeletal muscle capillarization and enzyme levels during training and detraining. Acta Physiol. Scand. 113, 9-16.

Korhonen, M. T., Cristea, A., Alen, M., Hakkinen, K., Sipila, S., Mero, A., Viitasalo, J. T., Larsson, L., and Suominen, H. (2006). Aging, muscle fiber type, and contractile function in sprint-trained athletes. J. Appl. Physiol. 101, 906-917.

Kortianou, E. A., Nasis, I. G., Spetsioti, S. T., Daskalakis, A. M., and Vogiatzis, I. (2010). Effectiveness of interval exercise training in patients with COPD. Cardiopulm. Phys. Ther. J. 21, 12-19.

Kupa, E. J., Roy, S. H., Kandarian, S. C., and De Luca, C. J. (1995). Effects of muscle fibre type and size on EMG median frequency and conduction velocity. J. Appl. Physiol. 79, 23-32.

Lamb, G. D., and Westerblad, H. (2011). Acute effects of reactive oxygen and nitrogen species on the contractile function of skeletal muscle. J. Physiol. (Lond.) 589, 2119-2127.

Laursen, P. B. (2010). Training for intense exercise performance: highintensity or high-volume training? Scand. J. Med. Sci. Sports 20, 1-10.

Lawler, J. M., Song, W., and Demaree, S. R. (2003). Hindlimb unloading increases oxidative stress and disrupts antioxidant capacity in skeletal muscle. Free Radic. Biol. Med. 35, 9-16.

Lawler, J. M., Song, W., and Kwak, H. B. (2006). Differential response of heat shock proteins to hindlimb unloading and reloading in the soleus. Muscle Nerve 33, 200-207.

Leterme, D., and Falempin, M. (1994). Compensatory effects of chronic electrostimulation on unweighted rat soleus muscle. Pflugers Arch. 426, 155-160.

Linossier, M. T., Denis, C., Dormois, D., Geyssant, A., and Lacour, J. R. (1993). Ergometric and metabolic adaptation to a 5 -s sprint training programme. Eur. J. Appl. Physiol. 67, 408-414.

Linossier, M. T., Dormois, D., Perier, C., Frey, J., Geyssant, A., and Denis, C. (1997). Enzyme adaptations of human skeletal muscle during bicycle short-sprint training and detraining. Acta Physiol. Scand. 161, 439-445.

MacDougall, J. D., Hicks, A. L., MacDonald, J. R., McKelvie, R. S., Green,
H. J., and Smith, K. M. (1998). Muscle performance and enzymatic adaptations to sprint interval training. J. Appl. Physiol. 84, 2138-2142.

Malek, M. H., Olfert, I. M., and Esposito, F. (2010). Detraining losses of skeletal muscle capillarization are associated with vascular endothelial growth factor protein expression in rats. Exp. Physiol. 95, 359-368.

Malisoux, L., Francaux, M., and Theisen, D. (2007). What do singlefibre studies tell us about exercise training? Med. Sci. Sports Exerc. 39, 1051-1060.

McCully, K. K., Iotti, S., Kendrick, K., Wang, Z., Posner, J. D., Leigh, J., and Chance, B. (1994). Simultaneous in vivo measurements of $\mathrm{HbO} 2$ saturation and $\mathrm{PCr}$ kinetics after exercise in normal humans. J. Appl. Physiol. 77, 5-10.

McCully, K. K., Kakihira, H., Vandenborne, K., and Kent-Braun, J. (1991). Noninvasive measurements of activity-induced changes in muscle metabolism. J. Biomech. 24, 153-161.

McKenna, M. J., Bangsbo, J., and Renaud, J. M. (2008). Muscle $\mathrm{K}^{+}$, $\mathrm{Na}^{+}$, and $\mathrm{Cl}$ disturbances and $\mathrm{Na}^{+}$. $\mathrm{K}^{+}$pump inactivation: implications for fatigue. J. Appl. Physiol. 104, 288-295.

McKenna, M. J., Schmidt, T. A., Hargreaves, M., Cameron, L., Skinner, S. L., and Kjeldsen, K. (1993). Sprint training increases human skeletal muscle $\mathrm{Na}+-\mathrm{K}+$-ATPase concentration and improves $\mathrm{K}+$ regulation. $J$. Appl. Physiol. 75, 173-180.

Mendez-Villanueva, A., Hamer, P., and Bishop, D. (2008). Fatigue in repeated-sprint exercise is related to muscle power factors and reduced neuromuscular activity. Eur. J. Appl. Physiol. 103, 411-419.

Metcalfe, R. S., Babraj, J. A., Fawkner, S. G., and Vollaard, N. B. (2011). Towards the minimal amount of exercise for improving metabolic health: beneficial effects of reducedexertion high-intensity interval training. Eur. J. Appl. Physiol. doi:10.1007/s00421-011-2254-z

Moholdt, T., Aamot, I. L., Granøien, I., Gjerde, L., Myklebust, G., Walderhaug, L., Brattbakk, L., Hole, T., Graven, T., Stolen, T. O., Amundsen, B. H., Molmen-Hansen, H. E., Stoylen, A., Wisloff, U., and Slordahl, S. A. (2012). Aerobic interval training increases peak oxygen uptake more than usual care exercise training in myocardial infarction patients: a randomized, controlled study. Clin. Rehabil. 26, 33-44.
Mohr, M., Krustrup, P., Nielsen, J. J., Nybo, L., Rasmussen, M. K., Juel, C. and Bangsbo, J. (2007). Effect of two different intense training regimens on skeletal muscle ion transport proteins and fatigue development. Am. J. Physiol. 292, R1594-R1602.

Moylan, J. S., and Reid, M. B. (2007). Oxidative stress, chronic disease, and muscle wasting. Muscle Nerve 35 , 411-429.

Mujika, I., and Padilla, S. (2001). Muscular characteristics of detraining in humans. Med. Sci. Sports Exerc. 33 1297-1303.

Nordlund, M. M., Thorstensson, A. and Cresswell, A. G. (2004). Central and peripheral contributions to fatigue in relation to level of activation during repeated maximal voluntary isometric plantar flexions. $J$. Appl. Physiol. 96, 218-225.

Ohira, Y., Yoshinaga, T., Nomura, T., Kawano, F., Ishihara, A., Nonaka, I., Roy, R. R., and Edgerton, V. R. (2002). Gravitational unloading effects on muscle fiber size, phenotype and myonuclear number. $A d v$. Space Res. 30, 777-781.

Osternig, L. R., Hamill, J., Lander, J. E., and Robertson, R. (1986). Coactivation of sprinter and distance runner muscles in isokinetic exercise. Med. Sci. Sports Exerc. 18, 431-435.

Paasuke, M., Ereline, J., and Gapeyeva, H. (1999). Twitch contractile properties of plantar flexor muscles in power and endurance trained athletes. Eur. J. Appl. Physiol. 80, 448-451.

Parolin, M. L., Chesley, A., Matsos, M. P. Spriet, L. L., Jones, N. L., and Heigenhauser, G. J. (1999). Regulation of skeletal muscle glycogen phosphorylase and PDH during maximal intermittent exercise. Am. J. Physiol. 277, E890-E900.

Pellegrino, M. A., Desaphy, J. F., Brocca, L., Pierno, S., Camerino, D. C., and Bottinelli, R. (2011). Redox homeostasis, oxidative stress and disuse muscle atrophy. J. Physiol. (Lond.) 589, 2147-2160.

Pette, D. (1985). Metabolic heterogeneity of muscle fibres. J. Exp. Biol. 115, 179-189.

Pette, D. (1998). Training effects on the contractile apparatus. Acta Physiol. Scand. 162, 367-376.

Pette, D., and Staron, R. S. (1997). Mammalian skeletal muscle fiber type transitions. Int. Rev. Cytol. 170, 143-223.

Pette, D., and Vrbova, G. (1999). What does chronic electrical stimulation teach us about muscle plasticity? Muscle Nerve 22, 666-677.
Picquet, F., and Falempin, M. (2003). Compared effects of hindlimb unloading versus terrestrial deafferentation on muscular properties of the rat soleus. Exp. Neurol. 182, 186-194.

Racinais, S., Bishop, D., Denis, R., Lattier, G., Mendez-Villaneuva, A., and Perrey, S. (2007). Muscle deoxygenation and neural drive to the muscle during repeated sprint cycling. Med. Sci. Sports Exerc. 39, 268-274.

Ratel, S., Lazaar, N., Williams, C. A., Bedu, M., and Duche, P. (2003). Age differences in human skeletal muscle fatigue during high-intensity intermittent exercise. Acta Paediatr. 92, 1248-1254.

Rimmer, J. H., Schiller, W., and Chen, M. D. (2012). Effects of disabilityassociated low energy expenditure deconditioning syndrome. Exerc. Sport Sci. Rev. 40, 22-29.

Ross, A., and Leveritt, M. (2001). Longterm metabolic and skeletal muscle adaptations to short-sprint training: implications for sprint training and tapering. Sports Med. 31, 1063-1082.

Roudier, E., Gineste, C., Wazna, A., Dehghan, K., Desplanches, D., and Birot, O. (2010). Angio-adaptation in unloaded skeletal muscle: new insights into an early and muscle type-specific dynamic process. $J$. Physiol. (Lond.) 588, 4579-4591.

Sahlin, K., Tonkonogi, M., and Söderlund, K. (1998). Energy supply and muscle fatigue in humans. Acta Physiol. Scand. 162, 261-266.

Sargeant, A. J. (2007). Structural and functional determinants of human muscle power. Exp. Physiol. 92, 323-331.

Simoneau, J. A., Lortie, G., Boulay, M. R., Marcotte, M., Thibault, M. C., and Bouchard, C. (1987). Effects of two high-intensity intermittent training programs interspaced by detraining on human skeletal muscle and performance. Eur. J. Appl. Physiol. 56, 516-521.

Simonson, E., and Weiser, P. (1976). Physiological Aspects and Physiological Correlates of Work Capacity and Fatigue. Springfield, IL: CC Thomas, 336-405.

Spencer, M., Bishop, D., Dawson, B., and Goodman, C. (2005). Physiological and metabolic responses of repeated-sprint activities: specific to field-based team sports. Sports Med. 35, 1025-1044.

Stein, T. P., and Wade, C. E. (2005) Metabolic consequences of muscle disuse atrophy. J. Nutr. 135, 1824S1828 S. 
Stepto, N. K., Hawley, J. A., Dennis, S. C., Hopkins, W. G. (1999). Effects of different interval-training programs on cycling time-trial performance. Med. Sci. Sports Exerc. 31, 736-741.

Stevens, L., Sultan, K. R., Peuker, H., Gohlsch, B., Mounier, Y., and Pette, D. (1999). Time-dependent changes in myosin heavy chain mRNA and protein isoforms in unloaded soleus muscle of rat. Am. J. Physiol. 277, C1044-C1049.

Tadaishi, M., Miura, S., Kai, Y., Kano, Y., Oishi, Y., and Ezaki, O. (2011). Skeletal muscle-specific expression of PGC-1a-b, an exercise-responsive isoform, increases exercise capacity and peak oxygen uptake. PLoS ONE 6, e28290. doi:10.1371/journal.pone. 0028290

Tesch, P. A., and Wright, J. E. (1983). Recovery from short term intense exercise: its relation to capillary supply and blood lactate concentration. Eur. J. Appl. Physiol. 52, 98-103.

Tesch, P. A., Wright, J. E., Vogel, J. A., Daniels, W. L., Sharp, D. S., and Sjodin, B. (1985). The influence of muscle metabolic characteristics on physical performance. Eur. J. Appl. Physiol. 54, 237-243.

Thomas, C., Bishop, D., Moore-Morris, T., and Mercier, J. (2007). Effects of high-intensity training on MCT1, MCT4, and NBC expressions in rat skeletal muscles: influence of chronic metabolic alkalosis. Am. J. Physiol. 293, E916-E22.

Tjonna, A. E., Lee, S. J., Rognmo, O., Stolen, T. O., Bye, A., Haram, P. M., Loennechen, J. P., Al-Share, Q. Y., Skogvoll, E., Slørdahl, S. A., Kemi, O. J., Najjar, S. M., and Wisloff, U. (2008). Aerobic interval training versus continuous moderate exercise as a treatment for the metabolic syndrome: a pilot study. Circulation 118, 346-354.

Tomlin, D. L., and Wenger, H. A. (2002). The relationships between aerobic fitness, power maintenance and oxygen consumption during intense intermittent exercise. J. Sci. Med. Sport 5, 194-203.

Trappe, S., Harber, M., Creer, A., Gallagher, P., Slivka, D., Minchev, K., and Whitsett, D. (2006). Single muscle fiber adaptations with marathon training. J. Appl. Physiol. $101,721-727$.

Urso, M. L. (2009). Disuse atrophy of human skeletal muscle: cell signaling and potential interventions. Med. Sci. Sports Exerc. 41, 1860-1868.

Vogiatzis, I. (2011). Strategies of muscle training in very severe COPD patients. Eur. Respir. J. 38, 971-975.
Vogiatzis, I., Terzis, G., Stratakos, G., Cherouveim, E., Athanasopoulos, D. Spetsioti, S., Nasis, I., Manta, P. Roussos, C., and Zakynthinos, S. (2011). Effect of pulmonary rehabilitation on peripheral muscle fiber remodeling in patients with COPD in GOLD stages II to IV. Chest 140, 744-752.

Ward, G. R., MacDougall, J. D., Sutton, J. R., Toews, C. J., and Jones, N. L. (1986). Activation of human muscle pyruvate dehydrogenase with activity and immobilization. Clin. Sci. 70, 207-210.

Westerblad, H., and Allen, D. G. (2011). Emerging roles of ROS/RNS in muscle function and fatigue. Antioxid. Redox Signal. 15, 2487-2499.

Widrick, J. J., Stelzer, J. E., Shoepe, T. C., and Garner, D. P. (2002). Functional properties of human muscle fibres after short-term resistance exercise training. Am. J. Physiol. 283, R408-R416.

Wisloff, U., Ellingsen, O., and Kemi, O. J. (2009). High-intensity interval training to maximize cardiac benefits of exercise training? Exerc. Sport Sci. Rev. 37, 139-146.

Wisloff, U., Støylen, A., Loennechen, J. P., Bruvold, M., Rognmo, O. Haram, P. M., Tjonna, A. E., Helgerud, J., Slørdahl, S. A., Lee, S.
J., Videm, V., Bye, A., Smith, G. L., Najjar, S. M., Ellingsen, O., and Skjaerpe, T. (2007). Superior cardiovascular effect of aerobic interval training versus moderate continuous training in heart failure patients: a randomized study. Circulation 115 , 3086-3094.

Conflict of Interest Statement: The author declares that the research was conducted in the absence of any commercial or financial relationships that could be construed as a potential conflict of interest.

Received: 20 January 2012; accepted: 27 April 2012; published online: 18 May 2012.

Citation: Bogdanis GC (2012) Effects of physical activity and inactivity on muscle fatigue. Front. Physio. 3:142. doi: 10.3389/fphys.2012.00142

This article was submitted to Frontiers in Striated Muscle Physiology, a specialty of Frontiers in Physiology.

Copyright (๑ 2012 Bogdanis. This is an open-access article distributed under the terms of the Creative Commons Attribution Non Commercial License, which permits non-commercial use, distribution, and reproduction in other forums, provided the original authors and source are credited. 